\title{
Beyond Physicians \\ The Effect of Licensing and Liability Laws on the Supply of Nurse Practitioners and Physician Assistants
}

\author{
Benjamin J. McMichael
}

MERCATUS WORKING PAPER

All studies in the Mercatus Working Paper series have followed a rigorous process of academic evaluation, including (except where otherwise noted) at least one double-blind peer review. Working Papers present an author's provisional findings, which, upon further consideration and revision, are likely to be republished in an academic journal. The opinions expressed in Mercatus Working Papers are the authors' and do not represent official positions of the Mercatus Center or George Mason University. 
Benjamin J. McMichael. "Beyond Physicians: The Effect of Licensing and Liability Laws on the Supply of Nurse Practitioners and Physician Assistants." Mercatus Working Paper, Mercatus Center at George Mason University, Arlington, VA, 2017.

\begin{abstract}
The increased use of nurse practitioners (NPs) and physician assistants (PAs) represents an important option for increasing access to healthcare. I explore the effect of two types of laws on the supply of NPs and PAs: (1) occupational licensing laws that limit the practices of NPs and PAs and (2) caps on noneconomic damages. I find that relaxing licensing laws to allow NPs to practice with less physician oversight increases the supply of NPs in areas with few practicing physicians by 60 percent - though the size of this increase decreases as the supply of physicians increases. I find a similar effect of licensing laws that grant greater PA autonomy on the supply of PAs, but this effect is not consistently statistically significant. Noneconomic damages caps increase the supply of both NPs and PAs by about 60 percent at the lowest levels of physician supply, but the size of this increase decreases as the physician supply grows. I also examine the effects of these laws on the probability that a county contains a health professional shortage area. The results of this analysis indicate that licensing laws have meaningful effects on access to care.
\end{abstract}

JEL codes: Ill, I18, J44, K13

Keywords: nurse practitioner, physician assistant, occupational licensing, malpractice

\title{
Author Affiliation and Contact Information
}

Benjamin J. McMichael

Postdoctoral Scholar

Owen Graduate School of Management, Vanderbilt University

benjamin.j.mcmichael@vanderbilt.edu

\section{Acknowledgments}

I wish to thank R. Lawrence Van Horn, W. Kip Viscusi, Peter Buerhaus, and James Blumstein for their guidance in developing this paper. I also wish to thank the participants of the 2015 American Law and Economics Association annual conference - especially Jill Horwitz - and several anonymous reviewers for comments and suggestions on earlier drafts of this paper.

Copyright 2017 by Benjamin J. McMichael and the Mercatus Center at George Mason University

This paper can be accessed at https://www.mercatus.org/publications/licensing-liability-laws -nurses-physician-assistants 


\title{
Beyond Physicians: The Effect of Licensing and Liability Laws on the Supply of Nurse Practitioners and Physician Assistants
}

\author{
Benjamin J. McMichael
}

\section{Introduction}

Over the last decade, access to healthcare has played a dominant role in the national health policy debate. For the most part, the debate concerning access has focused on laws directed at increasing an individual's ability to obtain health insurance (that is, the demand side of healthcare markets) and has ignored laws that govern healthcare providers (that is, the supply side of these markets). However, one supply-side policy that has gained prominence over the last decade is the increased use of nurse practitioners (NPs) and physician assistants (PAs) to increase the capacity of the healthcare system (see Gilman and Koslov 2014). NPs are registered nurses who have undergone additional training that usually results in a graduate degree; they can provide many of the services historically reserved to physicians. Similarly, PAs are healthcare providers who typically possess graduate degrees and can provide many of the healthcare services that physicians can provide. Because NPs and PAs function similarly to physicians in many settings but require significantly less training, increasing the supply of these providers can expand the capacity of the healthcare system more quickly than increasing the supply of physicians.

Two separate legal regimes, which vary substantially across states, may affect how the supply of NPs and PAs develops across the country. First, state occupational licensing laws determine what services members of certain professions may provide and under what conditions they may provide those services. In general, these laws can prevent unqualified and incompetent providers from treating patients, which can promote patient safety. However, restrictive licensing laws may also inhibit the ability of NPs and PAs to provide care and may discourage them from 
practicing in certain states, which can decrease access to care. Indeed, the Institute of Medicine (IOM), the National Governors Association (NGA), and the Federal Trade Commission (FTC) have noted that these laws may function as anticompetitive restrictions, increase the administrative burdens on NPs and PAs, and undermine the flexibility of these professionals in providing care (IOM 2011; Schiff 2012; Dunker, Krofah, and Isasi 2014; Gilman and Koslov 2014). In 2015, the US Supreme Court acknowledged in North Carolina State Board of Dental Examiners v. Federal Trade Commission [NC Board], 135 S. Ct. 1101 (2015), that licensing laws restricting the provision of certain services to specific professions can be anticompetitive. ${ }^{1}$ Two types of occupational licensing laws are particularly important for NPs and PAs because they directly affect how those medical professionals may provide care to patients. Physician supervision laws determine to what extent a physician must supervise a NP or PA, and prescription authority laws determine what medications NPs and PAs may prescribe to patients.

Second, state medical malpractice law determines the extent of providers' expected liability costs. Just like physicians, dentists, lawyers, and other professionals, NPs and PAs are subject to state tort law and may be sued for malpractice. The American Medical Association (AMA) asserts that physicians respond to rising liability costs by, among other things, relocating to states where tort reforms reduce providers' expected liability costs (AMA 2017). NPs and PAs may respond similarly, given that they are also subject to state tort law. However, while the effects of tort reforms on the physician workforce have been studied extensively (Helland and

\footnotetext{
${ }^{1}$ Following NC Board, state occupational licensing laws may be subject to antitrust scrutiny. However, NC Board subjects only those regulations passed by state agencies that are unsupervised by the state legislature or another arm of the state. In general, NC Board would apply to some laws that govern the authority of NPs and PAs to prescribe specific medications, as those laws are sometimes based on state regulations, but would not apply to most laws that govern the degree to which a physician must supervise the practice of an NP or PA, as those laws are often based on state statutes. Because NC Board was issued at the end of the time period analyzed here, I do not consider its impact further. For a more complete discussion of the potential effects of NC Board going forward, see Allensworth (2017).
} 
Seabury 2015), no prior work has examined the effects of malpractice liability and tort reforms on the supply of NPs and PAs.

This study extends the literature on occupational licensing laws and begins to fill the gap in the malpractice literature by empirically examining the effects of these two legal regimes on the supply of NPs and PAs. It is the first study to empirically analyze the effects of malpractice reforms on NPs and PAs, and it is the first to examine the effect of occupational licensing laws on the supply of practicing NPs and PAs across all 50 states over time. I find evidence that both licensing and liability laws affect the supply of NPs and PAs and that these effects vary with the supply of physicians. More specifically, I find that allowing NPs to practice without any physician supervision increases the supply of NPs by 61 percent in areas with low physician supply. However, as the supply of physicians increases, the positive effect of allowing NPs to practice independently decreases, which suggests that relaxing licensing laws increases access to healthcare professionals but has the most substantial impact in areas with fewer physicians. I find similar results for laws allowing PAs to practice with more autonomy, but the effects of relaxed licensing laws on PAs are not consistently statistically significant. For both NPs and PAs, I find consistent evidence that, at low levels of physician supply, noneconomic damages caps ${ }^{2}-$ generally considered the most effective tort reform —increase NP and PA supplies by approximately 58 percent and 60 percent, respectively. However, as the supply of physicians increases, the positive effect of noneconomic damages caps decreases.

To confirm that the observed increases in NP and PA supply translate into meaningful increases in access to care, I extend my analysis to consider whether relaxing licensing laws or enacting tort reforms decreases the probability that a county contains an area designated as a

\footnotetext{
${ }^{2}$ Noneconomic damages compensate plaintiffs for hard-to-quantify harms such as pain and suffering. Noneconomic damages caps prohibit courts from imposing noneconomic damages awards in excess of the cap amount.
} 
health professional shortage area (HPSA) for primary care by the Department of Health and Human Services (HHS). The HPSA results track the supply results, indicating that the increases in provider supply represent increases in individuals' access to healthcare. For example, at low levels of physician supply, allowing NPs to practice independently results in an approximate 14 percent decrease in the probability that a county contains an HPSA relative to the national average. These results suggest that the observed increases in NP supply effectively increase access to care.

\section{Background and Previous Research}

\section{NPs, PAs, and Occupational Licensing Laws}

Members of both the NP and PA professions may diagnose and treat patients, order and interpret tests, and write prescriptions. ${ }^{3}$ Currently, most NP and PA training programs involve graduatelevel training that ranges between 18 months and 3 years. NPs and PAs function similarly to physicians in a variety of settings, and clinical evidence has demonstrated that they often perform as well as—or better than — physicians in providing care within their education and training (Newhouse et al. 2011; Naylor and Kurtzman 2010). Over 175,000 NPs and 91,000 PAs were licensed to practice in 2016. NPs and PAs currently outnumber family and general practice physicians, and in many geographic areas, NPs and PAs are the principal providers of primary care services (Auerbach 2012). Relative to physicians, a greater proportion of NPs and PAs practice in primary care settings (Stange 2014), and NPs and PAs are more likely to provide care

\footnotetext{
${ }^{3}$ NPs are one type of advanced practice nurse (APN); APNs can also be called advanced practice registered nurses (APRNs). Other types of APNs include certified nurse midwives, certified registered nurse anesthetists, and clinical nurse specialists. These other types of APNs are generally regulated by different laws, and throughout my analysis, I consider only NPs, not other types of APNs.
} 
in rural and underserved areas than physicians (Larson et al. 2003; Grumbach et al. 2003;

Everett et al. 2009).

Although NPs and PAs function similarly to physicians in many settings, the occupational licensing laws governing their practices vary substantially across states. ${ }^{4}$ Two categories of licensing laws are particularly important: physician supervision laws govern the level of physician involvement in NP and PA practices, and prescription authority laws determine what medications NPs and PAs may prescribe to their patients. NP supervision laws fit into three basic groups: those requiring no physician supervision (independent practice), those requiring physician supervision of NPs only when they prescribe medications (prescription supervision), and those requiring physician supervision of all aspects of an NP's practice (complete supervision). Figure 1 provides an overview of the changes in physician supervision laws for NPs between 2001 and 2015 - the time period over which my analysis occurs - and table $\mathrm{A} 1$ in the online appendix ${ }^{5}$ provides a comprehensive list of changes in these laws over this time period.

PA laws similarly fit into three categories; however, the differences among categories are more nuanced, as all states require a PA to be supervised at all times by a physician. At the highest level of autonomy (remote practice), PAs may practice at remote sites with physician visits to that site required no more than monthly. At the intermediate level of autonomy (quasiremote practice), PAs may practice at sites geographically separate from their supervising physicians, but states with these laws impose additional restrictions that inhibit the ability of PAs to practice remotely on a regular basis. These restrictions include requirements that the PA be in

\footnotetext{
${ }^{4}$ Throughout my analysis, I treat the District of Columbia as a state.

5 The online appendix can be found on the author's SSRN website at https://papers.ssrn.com/sol3/papers.cfm? abstract_id=3005128.
} 
direct, personal contact with the supervising physician semi-weekly (or more often) or that the supervising physician practice at the same site as the PA for some percentage of the PA's practice time. At the lowest level of autonomy (onsite supervision), PAs may practice only if their supervising physicians are within a certain geographic area. Figure 1 provides an overview of the changes in physician supervision laws for PAs between 2001 and 2015, and table A1 in the online appendix provides an exhaustive list of legal changes over this period.

\section{Figure 1. Physician Supervision Laws}

\section{Panel A. Supervision Laws-Nurse Practitioners}

2001

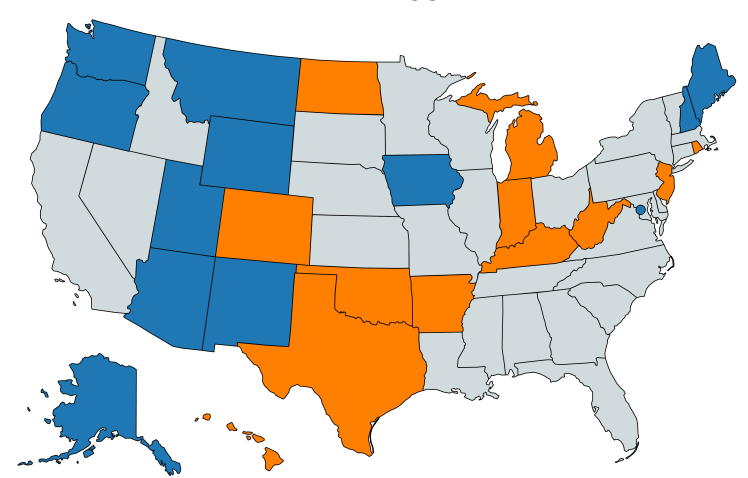

NP independence
RX supervision

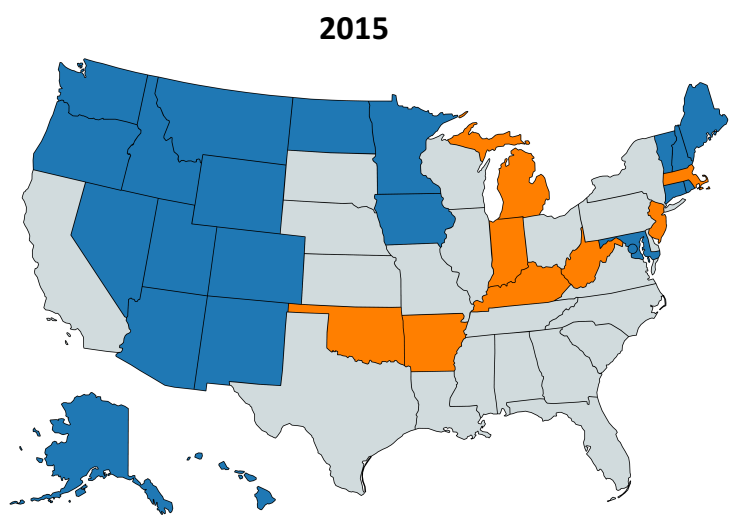

complete supervision 


\section{Panel B. Supervision Laws-Physician Assistants}

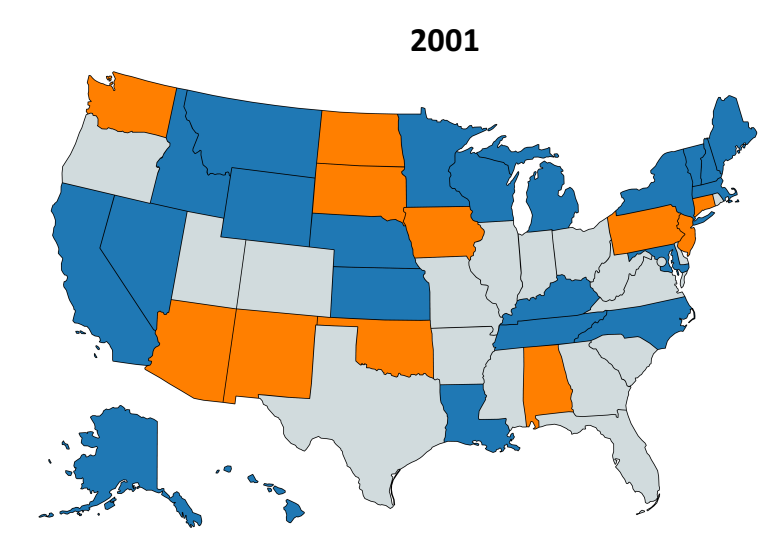

remote practice

quasi-remote practice

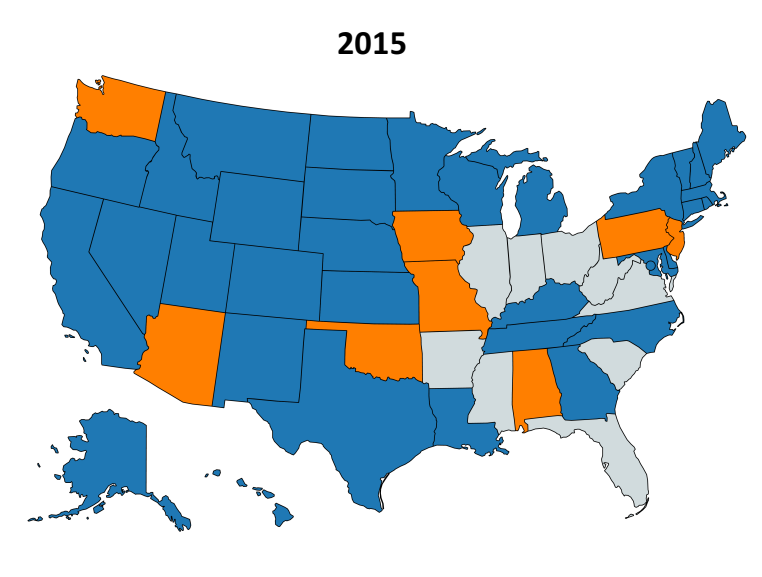

onsite supervision

Source: Author's analysis of state statutes, regulations, and court cases obtained from Westlaw and LexisNexis.

Although the nature of physician supervision laws differs for NPs and PAs since PAs can never practice independently, prescription authority laws affect both professions in the same way. For both NPs and PAs, states fall into one of two categories: those that grant these practitioners full authority to prescribe all legal controlled substances and those that limit this authority. States in the full-authority category authorize NPs and PAs to prescribe the same range of medications as physicians, while states in the limited-authority category restrict them to a greater extent than physicians. Figure 2 provides an overview of the changes in the prescription authority of NPs and PAs, while table A2 in the online appendix provides a full list of these changes. 
Figure 2. Prescription Authority Laws

Panel A. Prescription Authority-Nurse Practitioners

2001

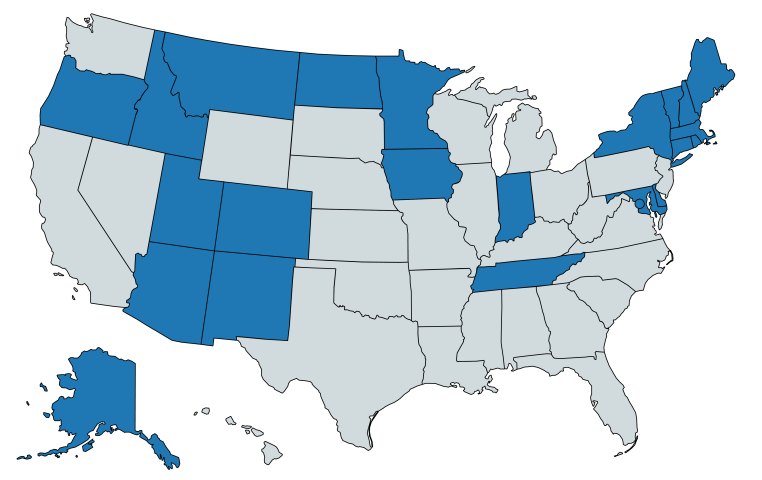

2015

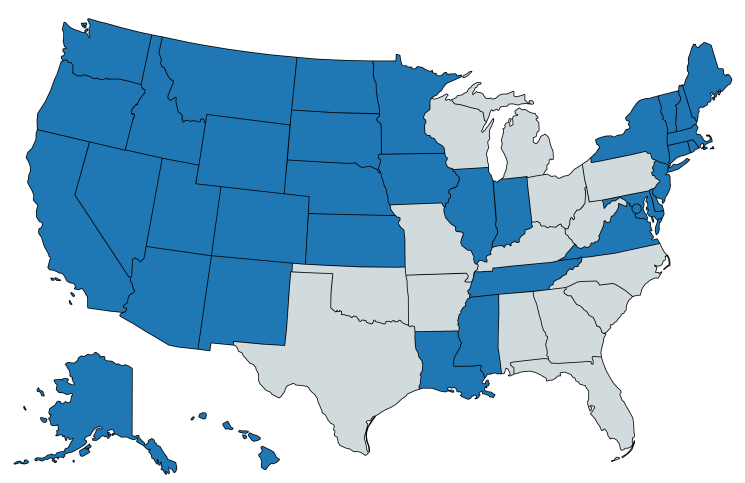

full controlled substances authority limited controlled substances authority

\section{Panel B. Prescription Authority—Physician Assistants}
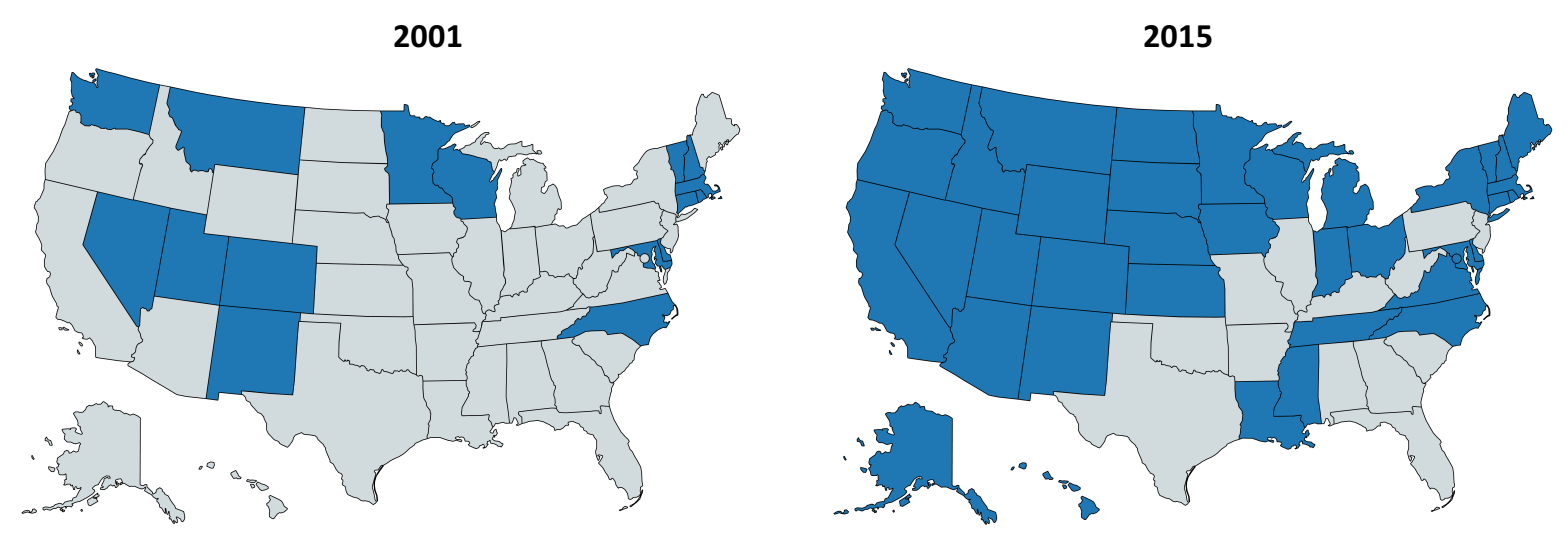

full controlled substances authority

limited controlled substances authority

Source: Author's analysis of state statutes, regulations, and court cases obtained from Westlaw and LexisNexis.

Two important patterns emerge from these two figures. First, the pattern of states relaxing physician supervision requirements for NPs and PAs and the pattern of states granting full prescription authority to NPs and PAs differ across the two professions, suggesting that states do not generally expand the authority of providers simultaneously. Second, the time period 
over which my analysis occurs includes substantial variation in state licensing laws, which provides the identifying variation for the difference-in-differences model discussed below.

The existing research on occupational licensing focuses primarily on licensing laws as barriers to entry rather than on their role in governing how individuals practice their profession or on how different professions interact with one another (see Kleiner 2006). However, some previous work has examined the effect of licensing laws on NPs and PAs and how they participate in healthcare markets. For example, Sekscenski et al. (1994) construct a state law index for PAs, NPs, and certified nurse midwives and find that broader licenses are positively correlated with the supply of providers. Declerq et al. (1998) focus on certified nurse midwives and find similar results. While both of these studies are cross-sectional, Kalist and Spurr (2004) use a fixed effects model to estimate the effect of broader advanced practice nurse (APN) licensing laws on enrollment in APN educational programs; they find that enrollment is 30 percent higher in states with broader licensing laws. All three of these studies consider data on the supply of NPs and PAs before 1997, when Congress authorized Medicare to reimburse NPs and PAs directly and when many insurance plans also began doing so (Frakes and Evans 2006). Before 1997, NPs and PAs could not be reimbursed without providing their services "incident to" the services provided by a physician, so any effect of changes in state laws before 1997 would have been muted by the fact that NPs and PAs were still tied to physicians based on federal law.

More recent research has focused on the effect of licensing laws on healthcare markets, and this work has uncovered mixed evidence of the effect of broader NP and PA licensing laws on these markets. Kleiner et al. (2016) find that when state laws allow NPs to perform more services without physician supervision, the price of a common medical examination decreases. 
They also consider the effect of these laws on the hours of care supplied by NPs and physicians. Traczynski and Udalova (2014) find that the number of routine checkups and other measures of healthcare quality and utilization increases when NPs can practice more autonomously. Stange (2014) finds that an increase in NP and PA supply has only small effects on the officebased healthcare market but has a larger effect on healthcare utilization in states that grant broader licenses. While Stange (2014) examines data on the number of NPs and PAs over an 18year period for 25 states (and more states in the later part of his period), he focuses primarily on the effect of changes in the supply of NPs and PAs and not on the determinants of supply.

This study extends earlier research on licensing laws in several ways. First, it builds on Stange's (2014) work using data over a shorter time period but covering all 50 states and the District of Columbia. It also examines a wider array of licensing laws when considering the effects of these laws on NP and PA supply. Second, it extends the analysis of Kleiner et al. (2016), who consider the effect of NP licensing laws on the hours of care supplied by NPs and physicians, to the effect of both NP and PA licensing laws on the number of providers. Understanding the latter effect is necessary to provide context for the former effect. Additionally, the effect of licensing laws on provider supply can provide insight into the competitive effects that drive the price decreases observed by Kleiner et al. (2016). Finally, while Traczynski and Udalova (2014) estimate some measures that relate to access to care, the analysis here directly considers the effect of licensing laws on access by directly examining both provider supply and the prevalence of HPSAs. 


\section{NP and PA Malpractice Liability}

When an NP or PA harms a patient, that patient may sue the NP or PA for malpractice, and as with physicians, states generally require NPs and PAs to maintain malpractice liability insurance. ${ }^{6}$ While almost no empirical evidence of the effect of malpractice liability on NPs and PAs exists, the effects of malpractice liability on the healthcare system and the potential of tort reform to dampen the negative effects have been debated for more than 30 years (Avraham and Schanzenbach 2010). Proponents of tort reforms, such as the AMA, assert that a greater potential for malpractice liability leads to, among other ill effects, physicians providing less care, practicing defensive medicine (which involves ordering unnecessary tests and procedures in order to reduce the risk of liability), retiring earlier, and relocating to places with lower malpractice costs (see Mello et al. 2006; Klick and Stratmann 2007). Tort reforms are designed to mitigate the effects of malpractice liability by decreasing the expected malpractice costs for healthcare providers. In this study, I focus on noneconomic damages caps, which have been generally established in the literature as the most effective tort reform (Mello 2006; Helland and Seabury 2015; Avraham and Schanzenbach 2015; Lieber 2014). These caps limit the ability of plaintiffs to recover damages for nonquantifiable injuries such as pain and suffering.

Prior work has demonstrated that noneconomic damages caps can effectively reduce malpractice liability risk. For example, Avraham (2007) finds that these caps reduce both the number and average size of malpractice payments (see also Mello 2006). Similarly, Born et al. (2009) find that noneconomic damages caps reduce medical malpractice losses and increase the profitability of medical malpractice insurers. Examining the effects of different tort reforms on the profitability of insurers, Viscusi and Born (2005) find that insurers pass on some of

\footnotetext{
${ }^{6}$ See, e.g., Conn. Gen. Stat. Ann. § 20-94c; Neb. Rev. Stat. Ann. § 38-2320. NPs and PAs generally pay out fewer awards and lower award amounts on average than do physicians (Hooker et al. 2009; Brock et al. 2017).
} 
the savings from lower malpractice liability payments to physicians. Not all studies find that noneconomic damages caps clearly reduce malpractice risk (see, e.g., Donohue and Ho 2007), and the effects of caps on the malpractice risk faced by NPs and PAs have not been subject to the same rigorous empirical analyses as their effects on physician malpractice risk. Nevertheless, NPs and PAs are subject to the same state tort law as physicians, suggesting that their malpractice risk will depend on state tort reforms in general and noneconomic damages caps in particular.

With respect to the effect of tort reform beyond malpractice payments, the existing studies focus almost exclusively on physicians. The evidence suggests that states with tort reforms have more physicians and higher physician growth (Helland and Seabury 2015; Lieber 2014). Klick and Stratmann (2007) and Encinosa and Hellinger (2005) find that states with noneconomic damages caps have more physicians. Similarly, Kessler, Sage, and Becker (2005) find evidence that "direct" tort reforms increase the supply of physicians. Reviewing the available evidence, Helland and Seabury (2015) note that much of the change in the supply of physicians as a result of tort reform is concentrated in rural areas (see also Matsa 2007) and among specialist physicians who face a higher risk of malpractice liability (see also Klick and Stratmann 2007). Conducting their own analysis, Helland and Seabury (2015) find evidence consistent with prior research—noneconomic damages caps increase the supply of physicians in high-risk specialties by between 2 percent and 7 percent—-but they note that additional research using new methods may better elucidate the true effect of noneconomic damages caps on physician supply. The need for this additional work is supported by some previous research that finds no evidence of an effect of tort reform on physician supply—even for physicians generally thought of as high risk (see, e.g., Yang et al. 2008). This study does not directly address the ongoing debate over the effect of tort reform on physician supply, but it broadens the scope of 
this debate to include NPs and PAs, who are assuming greater roles in the healthcare system alongside physicians.

\section{Data}

Information on NP and PA licensing laws comes directly from state statutes, regulations, and court cases obtained from Westlaw and LexisNexis. Using information directly from legal sources avoids problems of inconsistent statutory and regulatory interpretation that can arise when relying on secondary sources. Based on this information, I created a series of indicator variables for all of the licensing laws described above. If a given law was effective for less than six months, it is not coded as taking effect until the following year. I obtained information on noneconomic damages caps from the Database of State Tort Law Reforms (DSTLR) compiled by Avraham (2014). Because the amount cutoff for noneconomic damages caps varies, I use Avraham's (2014) “clever" definition of caps. These caps have been set low enough and have few enough exceptions to effectively limit damages awarded at trial.

Data on the supply of NPs, PAs, and physicians come from the Area Health Resource Files (AHRF), and throughout my analysis, I report all provider supply variables as the number of providers per 100,000 county residents. Physician supply data in the AHRF come from the Physician Masterfile compiled by the AMA, and these data have been used in previous research on physician supply (see, e.g., Matsa 2007). Information on the number of NPs and PAs in each county for the years 2010-2015 in the AHRF comes from the National Plan and Provider Enumeration System (NPPES) and includes all NPs and PAs with a national provider identifier (NPI). An NPI uniquely identifies a provider and, once obtained, remains with the provider for his or her entire career. With each NPI, the NPPES includes the provider's business address and 
the provider's type (physician, NP, or PA, among others). Beginning in 2007, all healthcare providers covered by the Health Insurance Portability and Accountability Act (HIPAA), which includes NPs and PAs, were required to acquire an NPI for use in all HIPAA-covered transactions. ${ }^{7}$ All providers are legally required to update their practice address when they change locations, so these data accurately track the movements of NPs and PAs.

Because the NPPES data only cover 2010 through 2015, I also use data included in the AHRF gathered by professional organizations for NPs in 2001 and PAs in 2001 and 2003. Including these additional years results in a temporal gap in the data but allows for more variation in state laws, which aids in the identification of my empirical models; Helland and Showalter (2009) adopted a similar strategy. In general, the time period covered by these data includes variation in both licensing laws and noneconomic damages caps. In particular, the variation in noneconomic damages caps occurs earlier in the data period, and the specific variation analyzed here has been referred to as being part of the "third wave" of tort reform (Paik et al. 2016).

In addition to information on the supply of physicians, NPs, and PAs, the AHRF includes information on whether any part of a particular county qualified as an HPSA for primary care, and the specifics of HPSAs are discussed in greater detail below. Finally, the AHRF contains information from which I construct the following demographic variables at the county level: population density, median household income, the percentage of the population identifying as

\footnotetext{
${ }^{7}$ Researchers conducted the National Sample Survey of Nurse Practitioners in 2012 and obtained information directly from state boards of nursing. They estimated that over 90 percent of all NPs had an NPI in 2012. The missing 10 percent may represent nonpracticing NPs. The National Sample Survey of Nurse Practitioners sampled NPs that were not currently practicing, and if these NPs had not practiced since 2007, they would not appear in the NPPES data. These estimates suggest that NPPES information on the number of NPs and PAs provides a complete picture of the total number of practicing NPs and PAs in the years I consider here.
} 
black or African-American, the percentage of the population identifying as Hispanic, and the percentage of the population eligible for Medicare.

\section{Analytic Framework and Expected Effects}

In this section, I provide a framework for analyzing licensing and liability laws in the context of NP and PA supply. In the empirical analysis, I examine the supply of NPs and the supply of PAs separately. However, because the laws affect these supplies similarly, I discuss the effects of these laws on the "supply of NPs and PAs." Within each subsection below, I address how the laws considered here may affect both the supply of NPs and PAs directly as well as the relationship between the supply of physicians and the supply of NPs and PAs. I explicitly consider the relationship between NP and PA supply and physician supply because, unlike other licensed professionals - lawyers, for example —who practice in markets limited exclusively to those professionals, all of the services that can be supplied by NPs and PAs can also be supplied by physicians.

NPs and PAs can be substitutes for or complements to physicians. ${ }^{8}$ Whether NPs and PAs are substitutes or complements for physicians is an open question in the literature. Most of the existing evidence suggests that both professions are complements to physicians, as the (disfavored) term "physician extender," which is sometimes applied to NPs and PAs, implies (see Stange 2014; Timmons 2017). Based on this evidence, I expect that an increase in physician supply will be associated with an increase in NP and PA supply. However, the nature of the complement or substitute relationship between NPs and PAs and physicians may depend on the

\footnotetext{
${ }^{8}$ For example, when an NP or PA provides follow-up care to a physician's patient, he or she is a complement to that physician. However, when a patient receives care for an illness from an NP or PA instead of a physician, that NP or PA is a substitute for the physician.
} 
occupational licensing laws or tort reforms in place. One way to view restrictive licensing laws is as a form of "compelled complements," as these laws tether NPs and PAs to physicians and prevent them from entirely substituting for physician-delivered care.

\section{Occupational Licensing Laws}

First, with respect to the direct effect of occupational licensing laws on the supply of NPs and PAs, I expect that relaxing or eliminating physician supervision requirements will increase the supply of NPs and PAs. I expect to find this effect because physician supervision laws may hinder the ability of NPs and PAs to provide care and may impose costs on these providers in three ways (see Kleiner et al. 2016): (1) physician supervision requirements tether NPs and PAs to their supervising physicians and may limit their ability to provide care in locations that are convenient for consumers (such as clinics within drugstores or grocery stores), in rural or isolated areas, outside of normal business hours, or in other settings where physicians have historically been unwilling to practice; (2) supervision laws impose administrative burdens and other costs on NPs and PAs; (3) supervision laws may effect a monetary transfer from NPs and PAs to physicians (see, e.g, Perry 2009; Dueker et al. 2005; Kleiner et al. 2016; Gilman and Koslov 2014). Given the costs associated with supervision, I hypothesize that reducing physician supervision requirements will increase the supply of NPs and PAs. However, I expect that relaxing these requirements will have a larger effect on NP supply than on PA supply for two reasons: PAs are tied more closely to their supervising physicians than NPs, and the marginal change from one level of supervision to another is smaller for PAs than NPs-unlike NPs, PAs can never practice independently. 
Similarly, I expect that increasing the prescription authority of NPs and PAs through more permissive laws will increase the supply of these providers. Restrictive prescription authority laws may hinder the ability of NPs and PAs to provide care by directly limiting the services NPs and PAs can provide — and thus the demand they can satisfy without working closely with physicians. Increasing the prescription authority of NPs and PAs allows these providers to supply a wider range of healthcare services and obviates the need for patients to see a physician in order to obtain certain medications, which should, in turn, allow the supply of NPs and PAs to increase.

Second, with respect to the effect of licensing laws on the relationship between NP and PA supply and physician supply, I expect that relaxing licensing laws will allow NPs and PAs to function more as substitutes for physicians than they otherwise could because, under more relaxed laws, they can both provide more services and require less physician involvement. If, as expected, NPs and PAs are complements to physicians, then an increase in physician supply should be associated with an increase in NP and PA supply. If relaxing licensing laws allows NPs and PAs to function more as substitutes for physicians, then the size of the increase in NP and PA supply associated with a given increase in physician supply should decrease (and potentially become negative). ${ }^{9}$ As with the general effect of relaxing licensing laws on NP and PA supply, I expect the change in the relationship between NP and PA supply and physician supply to be more pronounced for NPs.

If, as expected, relaxing licensing laws generally increases the supply of NPs and PAs and decreases the size of the increase associated with a given increase in physician supply (i.e.,

\footnotetext{
${ }^{9}$ If, on the other hand, NPs and PAs function as substitutes in general, then an increase in physician supply should be associated with a decrease in NP and PA supply, and the magnitude of this decrease should increase if relaxing licensing laws better allows NPs and PAs to function as substitutes.
} 
allows NPs and PAs to function more as substitutes), then licensing laws will generate the largest increases in NP and PA supply in the areas with the fewest practicing physicians. While this is a straightforward extension of the anticipated effects discussed above, ${ }^{10}$ it is also consistent with previous work, which has demonstrated that NPs and PAs are more likely to provide care in underserved areas (Larson et al. 2003; Grumbach et al. 2003; Everett et al. 2009) and that licensing laws generally impose higher costs on NPs and PAs in areas with fewer practicing physicians (Gilman and Koslov 2014). ${ }^{11}$ For example, finding a supervising physician may be difficult in underserved areas, and NPs and PAs may have to expend significant resources to comply with supervision requirements (e.g., traveling long distances). Indeed, the FTC has recognized that NPs "may find it particularly difficult to [secure physician supervision] in rural or other underserved areas where collaborating physicians are in short supply" (Gilman and Koslov 2014, 30). If NPs and PAs desire to work in underserved areas but cannot do so because of restrictive licensing laws, or if licensing laws impose relatively higher costs on NPs and PAs working in areas with fewer physicians, then relaxing those laws should generate larger increases in NP and PA supply in areas with fewer physicians.

\footnotetext{
${ }^{10}$ This is a straightforward extension because in areas of low physician supply, the direct effect of relaxing licensing laws will be more salient than the effect of physician supply on the supply of NPs and PAs. In areas with more physicians, the change in the relationship between NP and PA supply and physician supply will be more salient than the direct effect of licensing laws.

${ }^{11}$ In general, these underserved areas may include rural areas, inner cities, and others. While the effect of licensing laws on the care provided by NPs and PAs in all of these underserved areas is important, given the nature of the data analyzed here, I focus on the role of licensing laws in rural areas. Because my data provide information on provider supply at the county level, it is possible to examine the effect of licensing laws across entire counties, but this necessarily prevents me from analyzing smaller geographic areas, such as inner cities. Future work should investigate these questions further.
} 


\section{Noneconomic Damages Caps}

In general, enacting a noneconomic damages cap should increase the supply of NPs and PAs.

Though much of the existing evidence on the effect of noneconomic damages caps is specific to physicians (e.g., Avraham 2007), some evidence suggests that damages caps reduce malpractice risk generally (Born et al. 2009). The reduction in malpractice risk may therefore make states with these reforms more desirable locations to practice for NPs and PAs (see Matsa 2007; Lieber 2014). Thus, I expect noneconomic damages caps to increase NP and PA supply.

In general, the effect of noneconomic damages caps on NP and PA supply may be more pronounced than the effect on physician supply. Although NPs and PAs typically pay out fewer and smaller awards than physicians (Brock et al. 2017), they also generate less income than physicians, making smaller awards more salient to them. Additionally, if NPs and PAs are more likely than physicians to be employees of hospitals and other healthcare firms, they may see their employment prospects at these companies systematically change as firms alter their use of NPs and PAs following the passage of a noneconomic damages cap. ${ }^{12}$ Finally, as Danzon et al. (1990) and Matsa (2007) note, if market demand for healthcare services is inelastic, changes in cost (such as decreased expected liability) will not have very large effects on the supply of healthcare providers. As the market demand for healthcare services becomes more elastic, the effect of changes in cost on the supply of providers becomes larger. In general, the demand for physician services is likely more inelastic than the demand for NP or PA services, ${ }^{13}$ implying that the effect

\footnotetext{
${ }^{12}$ To the extent NPs and PAs are employees of hospitals and other healthcare firms, those firms may face some degree of vicarious (or direct) liability for the malpractice of NPs and PAs. Given this potential for liability, healthcare firms may increase their use of NPs and PAs following the passage of a noneconomic damages cap. ${ }^{13}$ For example, a significant increase in the price of an appendectomy will likely not have a substantial effect on the demand for this service, given the necessity of this service to preserve life. Therefore, an increase in the price of appendectomies will likely not have an effect on the supply of physicians providing this service. However, an increase in the price of visiting an NP at a retail health clinic may have a large effect on the demand for this service. In other words, the demand for services provided by physicians is likely less elastic than the demand for services provided by NPs and PAs.
} 
of changes in cost on physician supply should be smaller than the effect of changes in cost on NP and PA supply.

Next, with respect to the relationship between physician supply and NP and PA supply, the effect of noneconomic damages caps is technically ambiguous and depends on the risk preferences of NPs, PAs, and physicians with respect to malpractice and the willingness of individual providers to increase the number of hours of care they provide. However, assuming these are relatively similar across professions, noneconomic damages caps should increase the substitutability of NPs and PAs for physicians. Caps can decrease the malpractice risk associated with patients, making them more profitable to treat. If this causes physicians to treat some patients they otherwise would not have treated, and assuming that physicians get "first choice" of which patients they want to treat, then NPs and PAs will be able to substitute for physicians in supplying care to the patients whom physicians find unprofitable to treat.

Finally, if caps generally increase the supply of NPs and PAs and the substitutability of NPs and PAs for physicians, then, as with licensing laws, noneconomic damages caps should increase NP and PA supply most in areas with few physicians. This extension is also consistent with the existing evidence suggesting that changes in liability have the most salient effects in underserved areas because expected liability costs may represent a larger share of an individual provider's cost structure in these areas (Matsa 2007). If liability costs represent a larger share of a provider's cost structure, then reducing these costs will have a larger marginal impact on the profitability of providing care in underserved areas and, thus, on the supply of providers in those areas. Moreover, if NPs and PAs are more likely than physicians to treat underserved patients but are hesitant to do so because of the malpractice implications, this would also suggest that noneconomic damages caps will have a larger effect in areas with fewer physicians. 


\section{The Effect of Licensing and Liability Laws on NP and PA Supply}

Table 1 reports summary statistics for the supply of NPs and PAs across different licensing and liability regimes at the county level. Across my sample, there are, on average, approximately 38 NPs and 26 PAs per 100,000 county residents. The number of PAs per capita increases monotonically as the degree of physician supervision required decreases. While counties in states allowing independent NP practice have the largest supplies of NPs, states requiring complete physician supervision have more NPs than do states requiring only prescription supervision. States granting full controlled substances authority to NPs and PAs have approximately 32 percent and 46 percent more NPs and PAs, respectively, than those states granting only limited prescription authority. Similarly, states with noneconomic damages caps have more practicing NPs and PAs per capita than states that have not enacted this reform.

Table 1. Summary Statistics for the Distribution of Nurse Practitioners and Physician Assistants

\begin{tabular}{lcclcc}
\hline Nurse Practitioners & Mean & Std. Dev. & Physician Assistants & Mean & Std. Dev. \\
\hline Total NPs & 37.8 & 30.32 & Total PAs & 26.30 & 28.47 \\
\hline Supervision laws & & & & & \\
\hline NP independence & 42.65 & 31.39 & Remote practice & 31.27 & 27.46 \\
RX supervision & 34.40 & 26.62 & Restricted practice & 25.37 & 35.04 \\
Complete supervision & 37.49 & 30.92 & Onsite supervision & 18.31 & 22.03 \\
\hline Prescription authority & & & & & \\
\hline NP cont. subst. & 43.21 & 34.36 & PA cont. subst. & 32.13 & 27.84 \\
NP limited cont. subst. & 32.67 & 24.86 & PA limited cont. subst. & 21.90 & 28.14 \\
\hline Tort reform & & & & & \\
\hline Noneconomic cap & 39.04 & 29.54 & Noneconomic cap & 29.63 & 28.11 \\
No cap & 37.01 & 30.78 & No cap & 24.29 & 28.49 \\
\hline No & & &
\end{tabular}

Notes: Cont. subst. $=$ controlled substances. Std. Dev. $=$ standard deviation. $\mathrm{RX}=$ prescription. Each mean represents the mean number of NPs or PAs per 100,000 county residents. Each grouping of legal variables consists of mutually exclusive and collectively exhaustive categories. The differences between the mean number of NPs per capita and the mean number of PAs per capita for any set of licensing law regimes is statistically significant at the $p<0.001$ level. The difference between the mean number of NPs per capita and the mean number of PAs per capita in jurisdictions with noneconomic damages caps and those without caps is statistically significant at the $p<0.001$ level. 
Figure 3 provides preliminary evidence that NPs and PAs respond to licensing laws differently depending on the supply of physicians. Each panel of figure 3 separates counties into deciles based on the number of physicians in those counties and reports the average number of physicians and the average number of NPs for each decile. Across all three supervision regimes, counties in lower deciles have more NPs relative to physicians, and this phenomenon is more pronounced in states granting NPs more autonomy. Interestingly, in states allowing NP independence, counties in the first physician supply decile have more total providers (NPs and physicians) than counties in the second physician supply decile. Separating counties based on other legal regimes yields similar evidence, suggesting that licensing and liability laws may affect the supply of NPs and PAs differently across different levels of physician supply.

\section{Figure 3. Mean Number of Providers across Physician Deciles}

\section{Panel A. Complete Supervision}

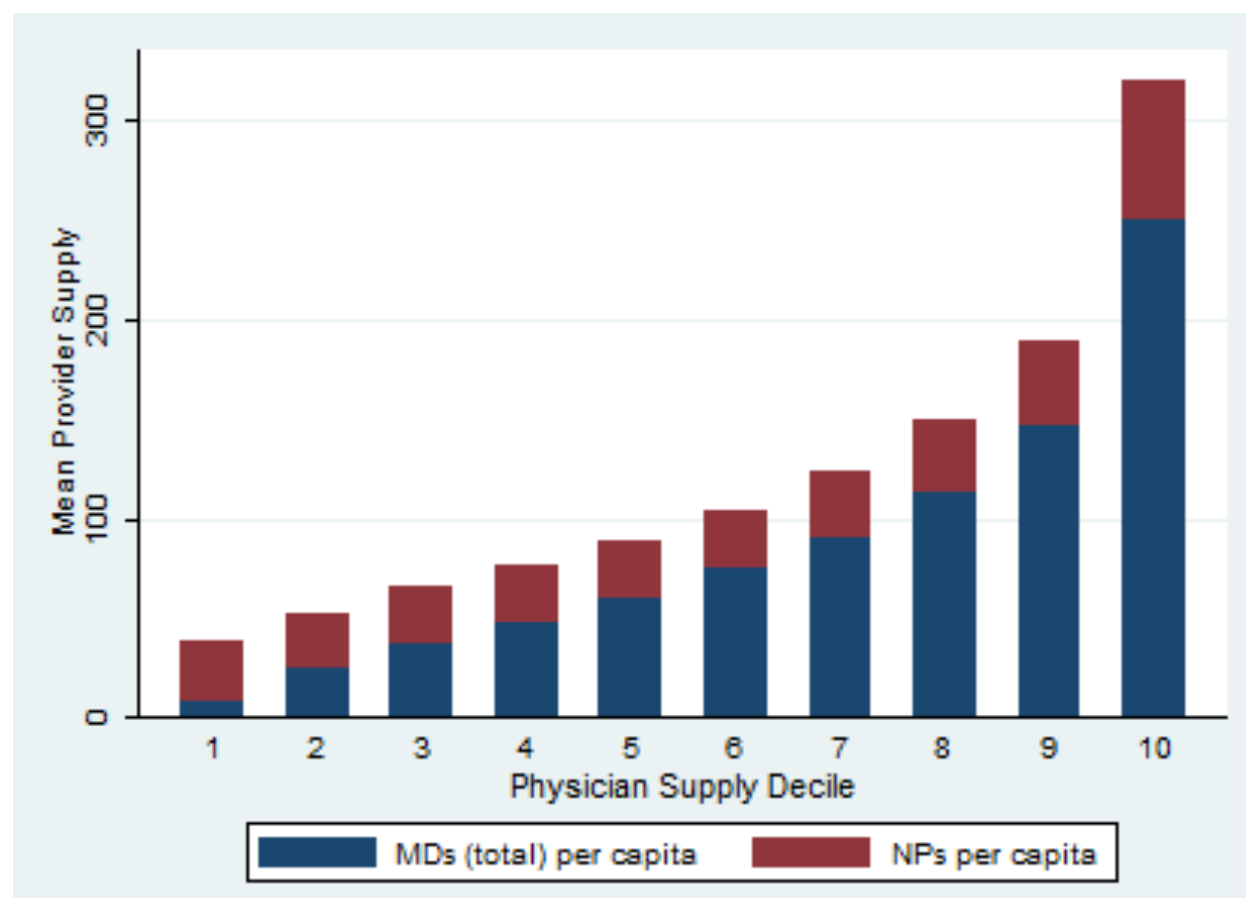




\section{Panel B. Prescription Supervision}

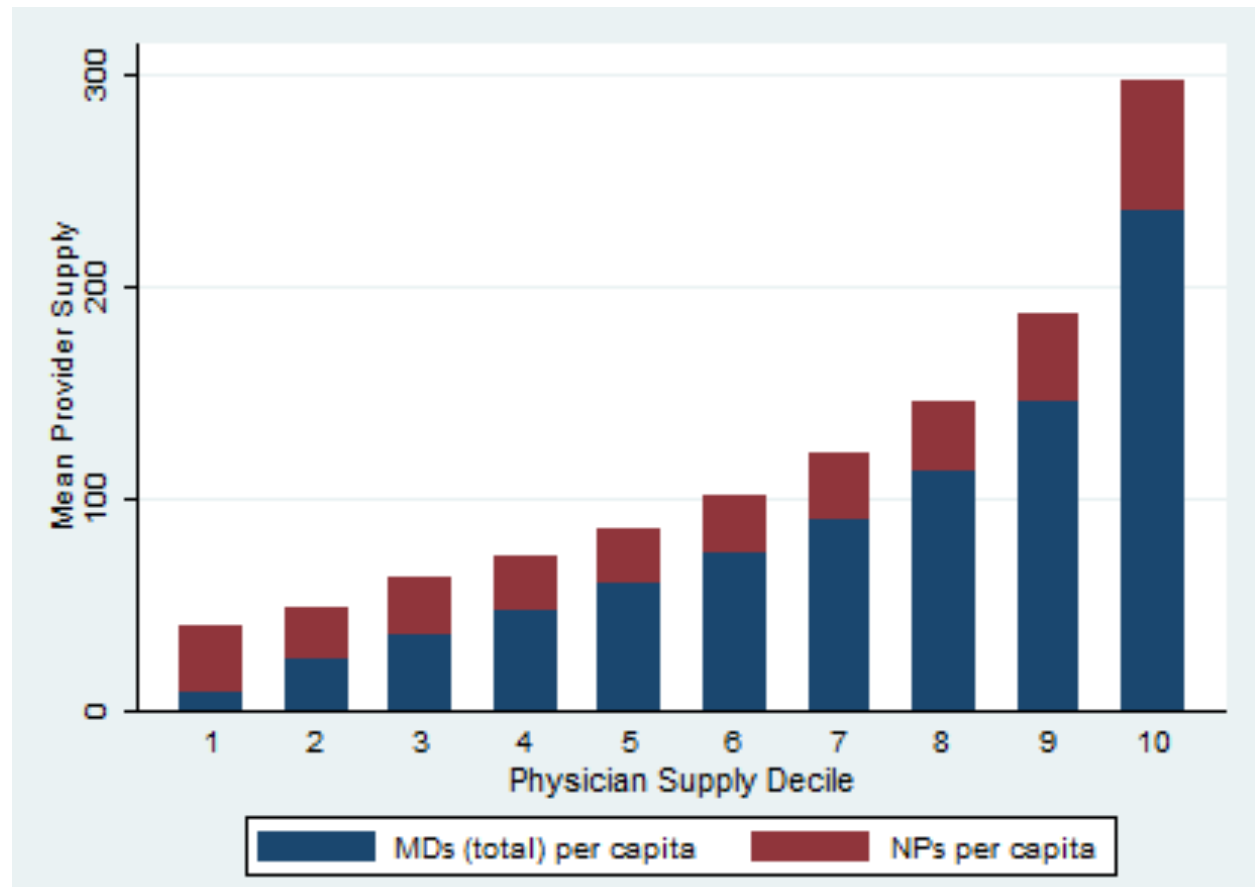

\section{Panel C. NP Independence}

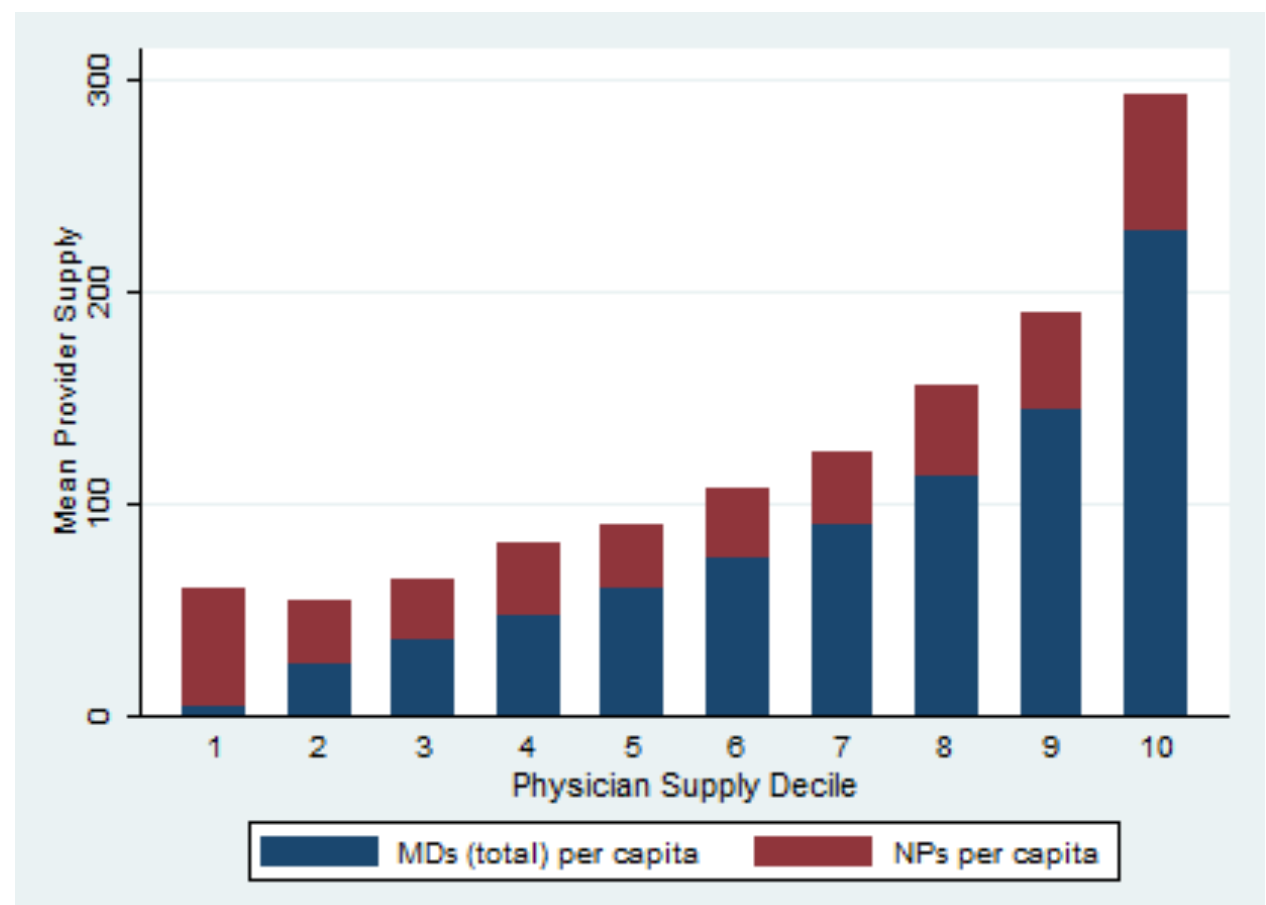

Source: Author's analysis of provider supply data contained in the AHRF. 


\section{Empirical Strategy}

My empirical analysis of the effects of licensing and liability laws on NP and PA supply proceeds in two parts. First, I examine the number of NPs and PAs per capita at the county level, excluding those counties with no practicing NPs or PAs. Second, I extend this analysis of provider supply to consider whether licensing and liability laws affect whether a given county contains an HPSA without excluding any counties from the analysis. I exclude counties with no NPs or PAs in the first part of my analysis because the Department of Health and Human Services (HHS) has recognized that it is not rational to provide healthcare in certain areas of the country (see 42 C.F.R. $§$ Pt. 5, App. A). Instead of imposing my own standards for whether a given county should have NPs or PAs practicing there, I first examine the supply of NPs and PAs conditional on having a nonzero supply, and then I separately look to see if licensing laws affect whether a county contains an HPSA, which by definition cannot exist in areas where it is not rational to supply care.

To isolate the causal effect of licensing and liability laws on the supply of NPs and PAs, I estimate two-way fixed effects models, which are generalizations of the traditional difference-indifferences model. These models control for fixed, unobserved characteristics of individual states and unobserved trends over time, and they can therefore provide estimates of the change in provider supply attributable to licensing and liability laws. I estimate separate models for NP supply and PA supply using the following general specification: 
(1) $\log (\text { provider supply })_{\mathrm{cst}}=$ licensing laws st $^{\prime} \beta_{1}+\beta_{2}$ nonecon cap $p_{s t}+$

$$
\begin{gathered}
\text { physician supply } y_{\text {cst }}^{\prime} \beta_{3}+ \\
(\text { licensing laws }) \times(\text { physician supply })_{c s t}^{\prime} \beta_{4}+ \\
(\text { nonecon cap }) \times(\text { physician supply })_{c s t}^{\prime} \beta_{5}+ \\
X_{c s t}^{\prime}+\delta_{s}+\tau_{t}+\varepsilon_{c s t}
\end{gathered}
$$

The dependent variable, log (provider supply) ${ }_{c s t}$, is the natural logarithm of the number of NPs or PAs per 100,000 county residents, where $c$ indexes counties, $s$ indexes states, and $t$ indexes time. The vector licensing $\boldsymbol{l a w s}_{\boldsymbol{s} t}$ includes indicator variables for supervision and prescription authority laws. For NPs, it includes indicators for NP independence and prescription supervision (with complete supervision as the omitted category). It also includes an indicator for full controlled substances authority. For PAs, this vector includes indicators for remote practice and quasi-remote practice (with onsite supervision as the omitted category). It also includes an indicator for whether PAs can prescribe all controlled substances. The variable nonecon cap st $_{\text {is }}$ an indicator for whether a state has enacted a noneconomic damages cap.

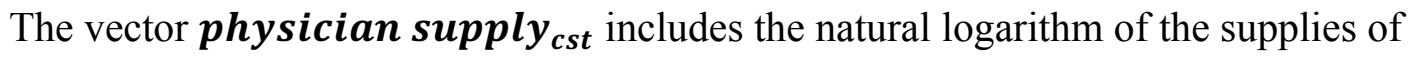
office-based and hospital-based physicians. ${ }^{14}$ I separate the physician supply in this way because the rules for billing for the services of NPs and PAs under Medicare (and many insurance plans) differ across these two settings, so an increase in the supply of office-based physicians may have

\footnotetext{
${ }^{14}$ Including physician supply as a predictor of NP and PA supply is consistent with the approach employed by Stange (2014) and Kleiner and Park (2010), who estimate a similar specification for the supply of dental hygienists and dentists when examining the licensing laws governing hygienists. When calculating the natural logarithm of the two physician supply variables, I add one to the number of physicians to avoid dropping counties with no practicing physicians. I do the same for NP and PA supply for consistency.
} 
a different effect than an increase in the supply of hospital-based physicians. ${ }^{15}$ Because NPs and PAs are most likely forward looking, the number of physicians is lagged one year. ${ }^{16}$ To allow licensing and liability laws to have different effects at different levels of physician supply, the model includes interactions between each legal indicator variable and each physician supply variable. The inclusion of the interaction terms also allows me to test whether the relationship between physician supply and NP and PA supply changes as licensing and liability laws change. $\boldsymbol{X}_{\boldsymbol{c s t}}$ is a vector of variables for population density, the natural logarithm of median household income, the percentage of the population identifying as black or African-American, the percentage of the population identifying as Hispanic, and the percentage of the population eligible for Medicare. As with the physician supply variables, these variables are lagged one year. Collectively, these variables control for population demographics that may affect the supply of healthcare providers. To control for fixed, unobserved determinants of provider supply across states and over time, I include state fixed effects, $\boldsymbol{\delta}_{\boldsymbol{s}}$, and year fixed effects, $\boldsymbol{\tau}_{\boldsymbol{t}}$. Throughout the analysis, I separately estimate models of NP supply and PA supply, ${ }^{17}$ and the standard errors in all models are clustered at the state level to correct for serial autocorrelation. ${ }^{18}$ The parameters of interest are $\beta_{1}$ through $\beta_{5}$, which represent the change in NP or PA supply associated with changes in licensing and liability laws across different levels of physician supply. In general, $\beta_{1}$ and $\beta_{2}$ capture the causal effect of licensing and liability laws on NP and

\footnotetext{
${ }^{15}$ Categorizing physicians separately as primary care, specialists, and surgeons does not change the qualitative nature of the results below.

${ }^{16}$ This is also necessary because of data limitations.

${ }^{17}$ I do not estimate population-weighted regressions because doing so involves assumptions about the error structure that may be violated here (see Wooldridge 2002). Matsa (2007) includes population-weighted regressions in his analysis of the supply of physicians, but Klick and Stratmann (2007) and Lieber (2014) do not.

${ }^{18}$ I also estimate (but do not report) all of the specifications reported below with bootstrapped standard errors to address concerns about small cell size. In all cases where an estimated coefficient reported below is statistically significant based on clustered standard errors, it is also statistically significant based on bootstrapped standard errors. Below, I also discuss models in which the standard errors are corrected for two-way clustering at the state and year levels.
} 
PA supply, $\beta_{3}$ captures the equilibrium (though not necessarily causal) relationship between physician supply and NP and PA supply, and $\beta_{4}$ and $\beta_{5}$ capture the causal effect of these laws on the relationship between NP and PA supply and physician supply. While I am able to estimate the causal effect of licensing and liability laws on the relationship between NP and PA supply and physician supply $-\beta_{4}$ and $\beta_{5}$-the available data do not allow me to fully investigate the specific mechanisms by which licensing and liability laws affect the equilibrium relationship between NP and PA supply and physician supply. Future work with different data may investigate these mechanisms in depth.

\section{Results and Discussion}

Nurse practitioner supply. Table 2 reports results from two-way fixed effects models with the natural logarithm of NP supply as the dependent variable. ${ }^{19}$ The specifications reported in panel A include only licensing law indicator variables, while the specifications in panel B include both licensing law indicators and an indicator for a noneconomic damages cap. Across all specifications, an increase in the supply of physicians is associated with an increase in the supply of NPs, which suggests, consistent with my expectations, that NPs and physicians are complements. Because both supply variables are in logarithmic form, the coefficient on physician supply is an elasticity. Thus, in column 1, a 10 percent increase in the supply of office-based physicians is associated with about a 1.5 percent increase in the supply of NPs, and

\footnotetext{
${ }^{19}$ Tables A3 and A4 in the online appendix report "naïve" specifications that do not allow the effects of different laws on NP or PA supply to vary with the supply of physicians. In general, no licensing laws have a statistically significant effect on NP or PA supply. Noneconomic damages caps do not impact the supply of NPs and have a negative effect on the supply of PAs. However, these specifications, by forcing licensing and liability laws to have the same effects across the range of physician supply, mask the true effects of these laws. As discussed above and demonstrated in figure 3, the effects of various laws on NP and PA supply likely vary depending on the supply of physicians.
} 
a 10 percent increase in hospital-based physicians is associated with about a 1.1 percent increase in NP supply. In states that allow NPs to practice independently, this elasticity decreases so that a 10 percent increase in the supply of office-based and hospital-based physicians increases the supply of NPs in only by 0.36 percent and 0.59 percent, respectively. ${ }^{20}$ This suggests that when NPs are less tightly connected to physicians, their decisions on where to practice are not driven as strongly by the presence of an existing supply of physicians and that relaxing licensing laws allows NPs to function more like substitutes to physicians. ${ }^{21}$ Although NP independence reduces the elasticity between physicians and NPs, allowing NPs to practice independently increases the total supply of NPs by 61 percent in general. ${ }^{22}$ Thus, at low levels of physician supply, amending licensing laws to allow NPs to practice independently substantially increases the supply of NPs. As the supply of physicians increases, the size of the increase in NP supply as a result of allowing NPs to practice independently becomes smaller.

\footnotetext{
${ }^{20}$ Throughout the empirical analysis, I test the joint statistical significance of individual licensing and liability law indicator variables and the interaction between these variables and measures of physician supply using F-tests of joint significance. In general, whenever a legal indicator variable and interaction between this variable and a measure of physician supply are individually statistically significant, I am able to reject the null hypothesis that the joint effect of these two variables is zero. In the interest of succinctness, I do not separately report the results of these F-tests.

${ }^{21}$ This interpretation assumes that licensing laws do not affect physician supply. I verify this assumption in the section on endogeneity below.

${ }_{22}$ Because the dependent variable is in logarithmic form, the marginal effect of an indicator variable with coefficient $\beta$ is approximately $((\exp (\beta)-1)(100))$ percent (Halvorsen and Palmquist 1980).
} 
Table 2. Regression Results for the Effect of Nurse Practitioner Laws on the Supply of Nurse Practitioners

Panel A. Licensing Laws Only

\begin{tabular}{|c|c|c|c|c|c|}
\hline & $\begin{array}{c}(1) \\
\log (N P s)\end{array}$ & $\begin{array}{c}(2) \\
\log (N P s)\end{array}$ & $\begin{array}{c}(3) \\
\log (N P s)\end{array}$ & $\begin{array}{c}(4) \\
\log (N P s)\end{array}$ & $\begin{array}{c}(5) \\
\log (N P s)\end{array}$ \\
\hline \multirow[t]{2}{*}{ NP independence } & $0.474^{* * *}$ & & $0.358^{* *}$ & $0.511^{* * *}$ & $0.395^{* *}$ \\
\hline & $(0.161)$ & & $(0.171)$ & $(0.171)$ & (0.178) \\
\hline \multirow[t]{2}{*}{ RX supervision } & & & & 0.156 & 0.197 \\
\hline & & & & $(0.158)$ & $(0.160)$ \\
\hline \multirow[t]{2}{*}{ NP cont. subst. } & & 0.256 & 0.093 & & 0.108 \\
\hline & & $(0.204)$ & $(0.194)$ & & (0.196) \\
\hline \multirow[t]{2}{*}{ (Independence $) \times \log ($ MDs office $)$} & $-0.112 * * *$ & & $-0.089 * *$ & $-0.119 * * *$ & $-0.095^{* *}$ \\
\hline & $(0.035)$ & & $(0.036)$ & $(0.038)$ & $(0.038)$ \\
\hline \multirow[t]{2}{*}{ (Independence $) \times \log ($ MDs hospital) } & $-0.046^{* *}$ & & $-0.038^{*}$ & $-0.046 * *$ & $-0.039 *$ \\
\hline & $(0.018)$ & & $(0.021)$ & $(0.020)$ & $(0.021)$ \\
\hline \multirow[t]{2}{*}{ (RX Supervision) $\times \log ($ MDs office $)$} & & & & -0.035 & -0.040 \\
\hline & & & & $(0.038)$ & $(0.039)$ \\
\hline \multirow[t]{2}{*}{ (RX Supervision) $\times \log ($ MDs hospital) } & & & & 0.004 & -0.002 \\
\hline & & & & $(0.018)$ & (0.019) \\
\hline \multirow[t]{2}{*}{ (NP Cont. Subst. $) \times \log ($ MDs office $)$} & & $-0.075^{*}$ & -0.039 & & -0.043 \\
\hline & & $(0.038)$ & $(0.038)$ & & (0.039) \\
\hline \multirow[t]{2}{*}{ (NP Cont. Subst.) $\times \log ($ MDs hospital) } & & -0.027 & -0.014 & & -0.015 \\
\hline & & $(0.019)$ & $(0.020)$ & & $(0.021)$ \\
\hline \multirow[t]{2}{*}{$\log (\mathrm{MDs}$ office) } & $0.148^{* * *}$ & $0.163^{* * *}$ & $0.164^{* * *}$ & $0.155^{* * *}$ & $0.174 * * *$ \\
\hline & $(0.023)$ & $(0.033)$ & $(0.033)$ & $(0.024)$ & $(0.035)$ \\
\hline \multirow[t]{2}{*}{$\log (\mathrm{MDs}$ hospital) } & $0.105^{* * *}$ & $0.111^{* * *}$ & $0.111^{* * *}$ & $0.105^{* * *}$ & $0.112 * * *$ \\
\hline & $(0.011)$ & $(0.015)$ & $(0.015)$ & $(0.013)$ & (0.019) \\
\hline Observations & 19,909 & 19,909 & 19,909 & 19,909 & 19,909 \\
\hline R-squared & 0.332 & 0.330 & 0.334 & 0.333 & 0.335 \\
\hline
\end{tabular}

Panel B. Licensing and Liability Laws

\begin{tabular}{lcccccc}
\hline & $(1)$ & $(2)$ & $(3)$ & $(4)$ & $(5)$ & $(6)$ \\
& $\log (\mathrm{NPs})$ & $\log (\mathrm{NPs})$ & $\log (\mathrm{NPs})$ & $\log (\mathrm{NPs})$ & $\log (\mathrm{NPs})$ & $\log (\mathrm{NPs})$ \\
\hline NP independence & & $0.414^{* * *}$ & & $0.282^{*}$ & $0.490^{* * *}$ & $0.352^{* *}$ \\
& & $(0.154)$ & & $(0.162)$ & $(0.161)$ & $(0.171)$ \\
RX supervision & & & & $0.294^{*}$ & $0.342^{* *}$ \\
& & & & $(0.163)$ & $(0.164)$
\end{tabular}




\begin{tabular}{|c|c|c|c|c|c|c|}
\hline \multirow[t]{2}{*}{ NP cont. subst. } & & & 0.262 & 0.125 & & 0.146 \\
\hline & & & $(0.176)$ & (0.169) & & $(0.167)$ \\
\hline \multirow[t]{2}{*}{ Nonecon. cap } & $0.457 * * *$ & $0.399 * *$ & $0.448 * * *$ & $0.407 * * *$ & $0.446 * * *$ & $0.463 * * *$ \\
\hline & $(0.161)$ & (0.151) & $(0.142)$ & $(0.144)$ & $(0.151)$ & $(0.146)$ \\
\hline \multirow[t]{2}{*}{$\begin{array}{l}\text { (Independence) } \times \\
\log (\text { MDs office })\end{array}$} & & $-0.100 * * *$ & & $-0.074 * *$ & $-0.109 * * *$ & $-0.081^{* *}$ \\
\hline & & $(0.031)$ & & $(0.033)$ & $(0.033)$ & $(0.035)$ \\
\hline \multirow[t]{2}{*}{$\begin{array}{l}\text { (Independence) } \times \\
\text { log(MDs hospital) }\end{array}$} & & $-0.043^{* *}$ & & -0.033 & $-0.043^{* *}$ & -0.034 \\
\hline & & (0.019) & & $(0.021)$ & $(0.020)$ & $(0.021)$ \\
\hline \multirow[t]{2}{*}{$\begin{array}{l}\text { (RX Supervision) } \times \\
\text { log(MDs office) }\end{array}$} & & & & & -0.050 & -0.058 \\
\hline & & & & & $(0.036)$ & $(0.036)$ \\
\hline \multirow[t]{2}{*}{$\begin{array}{l}\text { (RX Supervision) } \times \\
\log (\text { MDs hospital) }\end{array}$} & & & & & 0.003 & -0.004 \\
\hline & & & & & $(0.018)$ & $(0.020)$ \\
\hline \multirow[t]{2}{*}{$\begin{array}{l}\text { (NP Cont. Subst.) } \times \\
\log (\text { MDs office })\end{array}$} & & & $-0.074 * *$ & -0.044 & & -0.050 \\
\hline & & & $(0.032)$ & $(0.032)$ & & $(0.033)$ \\
\hline \multirow[t]{2}{*}{$\begin{array}{l}\text { (NP Cont. Subst.) × } \\
\log (\text { MDs hospital) }\end{array}$} & & & -0.029 & -0.017 & & -0.020 \\
\hline & & & $(0.018)$ & (0.019) & & $(0.020)$ \\
\hline \multirow[t]{2}{*}{$\begin{array}{l}\text { (Nonecon. Cap) } \times \\
\log (\text { MDs office) }\end{array}$} & $-0.084 * * *$ & $-0.071 * *$ & $-0.083^{* * *}$ & $-0.074 * * *$ & $-0.077^{* * *}$ & $-0.080 * * *$ \\
\hline & $(0.030)$ & $(0.027)$ & $(0.026)$ & $(0.026)$ & $(0.028)$ & $(0.027)$ \\
\hline \multirow[t]{2}{*}{$\begin{array}{l}\text { (Nonecon. Cap) } \times \\
\log (\text { MDs hospital) }\end{array}$} & -0.014 & -0.010 & -0.016 & -0.012 & -0.010 & -0.013 \\
\hline & $(0.020)$ & $(0.020)$ & $(0.020)$ & $(0.019)$ & $(0.020)$ & $(0.020)$ \\
\hline \multirow[t]{2}{*}{$\log (M D s$ office) } & $0.166 * * *$ & $0.182^{* * *}$ & $0.205^{* * *}$ & $0.201^{* * *}$ & $0.195^{* * *}$ & $0.218^{* * *}$ \\
\hline & $(0.022)$ & $(0.022)$ & $(0.031)$ & $(0.031)$ & $(0.023)$ & $(0.031)$ \\
\hline \multirow[t]{2}{*}{ log(MDs hospital) } & $0.100 * * *$ & $0.106 * * *$ & $0.115^{* * *}$ & $0.113^{* * *}$ & $0.106 * * *$ & $0.116 * * *$ \\
\hline & $(0.012)$ & $(0.013)$ & $(0.017)$ & $(0.017)$ & $(0.016)$ & $(0.021)$ \\
\hline Observations & 19,909 & 19,909 & 19,909 & 19,909 & 19,909 & 19,909 \\
\hline R-squared & 0.330 & 0.336 & 0.335 & 0.338 & 0.337 & 0.339 \\
\hline
\end{tabular}

Notes: Cont. subst. $=$ controlled substances. $\mathrm{RX}=$ prescription. The dependent variable in all specifications is the natural logarithm of the number of NPs per 100,000 county residents. Similarly, all physician supply variables are measured in the number of physicians per 100,000 county residents. Counties with no practicing NPs are excluded. All specifications include state and year fixed effects. Additional covariates include population density, the natural logarithm of median household income, the percentage of the population identifying as black or African-American, the percentage of the population identifying as Hispanic, and the percentage of the population eligible for Medicare. Standard errors clustered by state are reported in parentheses. $* * *=$ significant at 1 percent level; $* *=$ significant at 5 percent level; * = significant at 10 percent level. 
Figure 4 reports simple linear regression lines and illustrates the relationship between the supply of NPs and the supply of physicians more clearly. Allowing NPs to practice independently essentially flattens the relationship between NP and physician supply while generally increasing the number of NPs. At low levels of physician supply, NP independence increases the supply of NPs substantially. The size of this increase decreases as physician supply grows, and at the highest levels of physician supply, enacting NP independence actually reduces NP supply. Based on the regression results in column 1, the effect of enacting NP independence on NP supply ceases to be positive when the supply of office-based physicians exceeds approximately 70 physicians per 100,000 county residents - approximately the 60 th percentile of physician supply.

\section{Figure 4. Relationship between NP and Physician Supply by NP Independence}

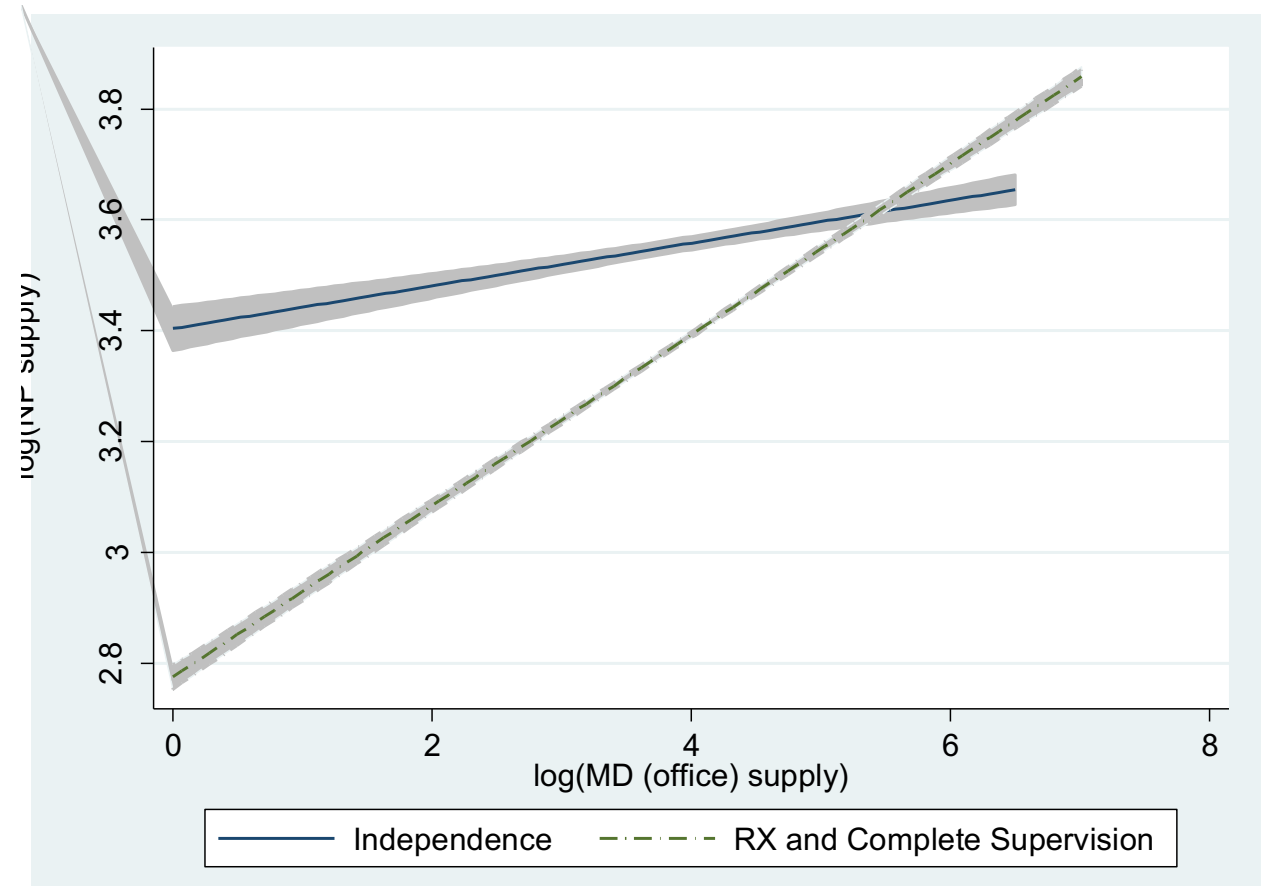

Notes: Each reported line comes from a simple linear regression, and the shaded area represents the 95 percent confidence interval.

Source: Author's analysis of provider supply data contained in the AHRF. 
Table 2 and figure 4 suggest that once NPs are untethered from physicians, the supply of NPs increases dramatically in areas that are relatively underserved by physicians but does not change drastically in areas that are saturated with physicians. The positive effect of NP independence at low levels of physician supply and negative effect at high levels of physician supply are both consistent with NPs relocating to relatively underserved areas when they no longer have to remain in areas with more physicians in order to secure supervision services. These effects are also consistent with NPs moving to areas where they are better able to meet patient demand for care-i.e., areas with fewer physicians per capita. The effects of the NP independence indicator and the interaction of this variable with physician supply are consistent across the range of specifications reported in panels $\mathrm{A}$ and $\mathrm{B}$ of table 2.

Allowing NPs to practice with physicians supervising only their prescribing activitiesthe intermediate level of physician supervision for NPs—-follows a similar pattern as NP independence; although, the effect of prescription supervision is not statistically significant in all specifications. In every specification, the magnitude of the effect of prescription supervision is smaller than NP independence while remaining positive, suggesting that NPs prefer to practice in prescription supervision states over complete supervision states and in independence states over prescription supervision states. Overall, the results for NP supervision laws are consistent with the predicted effects, and the evidence reported here indicates that relaxing physician supervision laws for NPs can increase the supply of NPs in areas that have less access to physicians. The results also support the hypothesis that NPs are complements to physicians but function more like substitutes when licensing laws are relaxed.

Allowing NPs to prescribe all controlled substances follows a similar pattern as allowing NPs to practice with less physician supervision; granting this authority increases the supply of 
NPs at low levels of physician supply. While this is consistent with the predicted effect and the coefficient on full controlled substances authority remains stable across all specifications, the effect is never statistically significant.

Panel B repeats all of the specifications from panel A but includes an indicator for whether a state had enacted a noneconomic damages cap. Across all specifications, the effect of enacting a noneconomic damages cap on NP supply follows essentially the same pattern as the effect of granting NPs independence. Focusing on column 1 of panel B, enacting a noneconomic damages cap reduces the estimated elasticity between the supply of office-based physicians and the supply of NPs from 0.166 to 0.082 , but it increases the general supply of NPs by 58 percent. Figure 5 illustrates this relationship more clearly. Noneconomic damages caps increase the supply of NPs when the supply of physicians is low, and the size of the increase in NP supply decreases as the supply of physicians increases. The effect of noneconomic damages caps on NP supply at low levels of physician supply is consistent with liability costs representing a larger share of an individual provider's cost structure in underserved areas (see Matsa 2007), as a reduction in liability costs leads to a substantial increase in NP supply in these areas. 
Figure 5. Relationship between NP and Physician Supply by Noneconomic Damages Cap

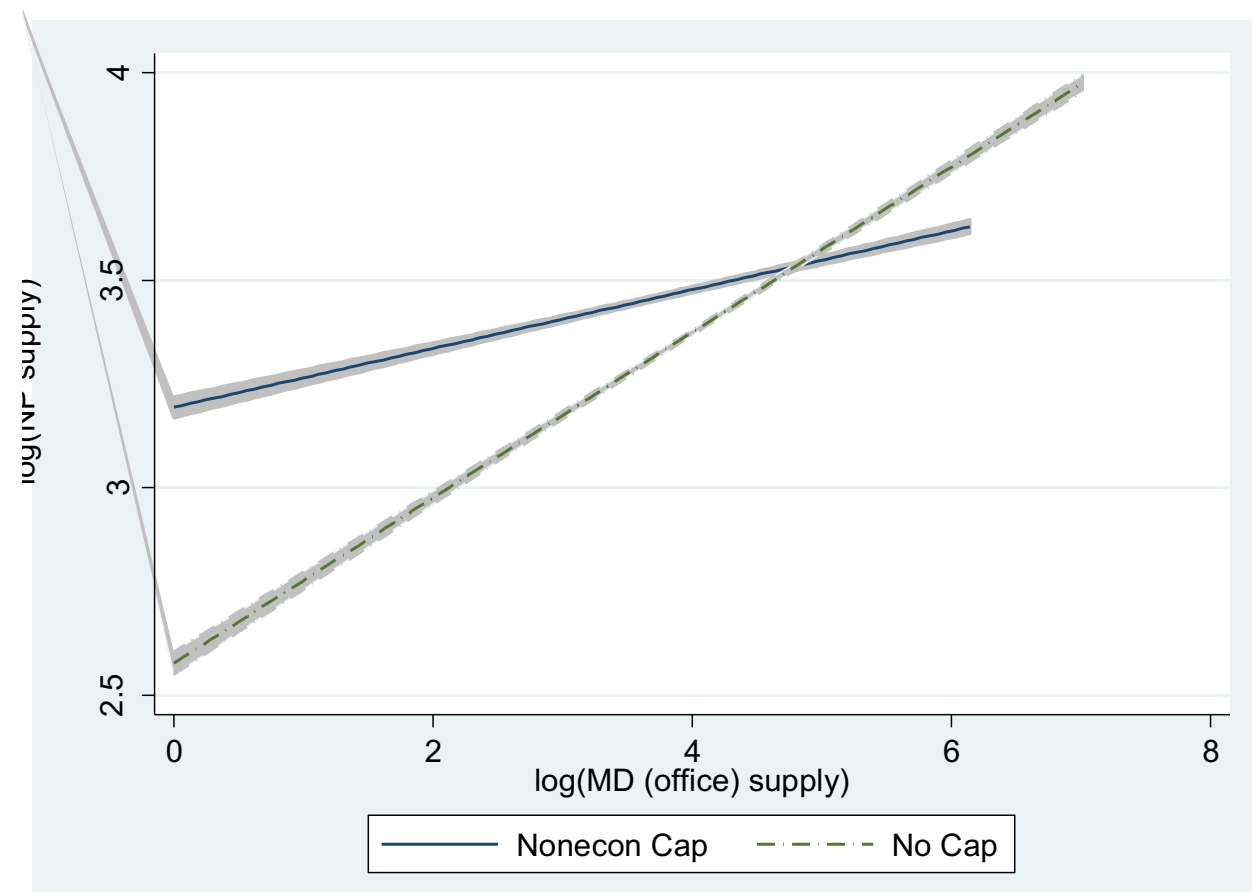

Notes: Each reported line comes from a simple linear regression, and the shaded area represents the 95 percent confidence interval.

Source: Author's analysis of provider supply data contained in the AHRF.

Physician assistant supply. Table 3 reports results from a series of two-way fixed effects models with the natural logarithm of PA supply as the dependent variable. As with NPs, an increase in the supply of physicians is associated with an increase in the supply of PAs. In general, allowing PAs to practice remotely has essentially the same effect on the supply of PAs as allowing NPs to practice independently has on the supply of NPs. At low levels of physician supply, allowing PAs to practice remotely results in a substantial increase in the number of PAs per capita (45 percent in column 4 of panel A) while reducing the elasticity between physician supply and PA supply. However, unlike NP independence, the coefficient on remote practice is not consistently statistically significant, so the evidence that allowing PAs to practice remotely affects PA supply is, at best, weak. Similarly, allowing PAs to practice quasi-remotely (the intermediate level of 
supervision) has a comparable effect on the supply of PAs as requiring only prescription supervision for NPs has on the supply of NPs. The weaker results for physician supervision laws for PAs are consistent with my expectations, as the marginal change in supervision requirements from one level to the next for PAs is smaller than for NPs - unlike NPs, PAs can never practice independently. Given this smaller marginal change, it is not surprising that the effect of a change in physician supervision laws for PAs has a weaker effect than a change in supervision laws for NPs.

Table 3. Regression Results for the Effect of Physician Assistant Laws on the Supply of Physician Assistants

Panel A. Licensing Laws Only

\begin{tabular}{|c|c|c|c|c|c|}
\hline & $\begin{array}{c}(1) \\
\log (\mathrm{PAs})\end{array}$ & $\begin{array}{c}(2) \\
\log (P A s)\end{array}$ & $\begin{array}{c}(3) \\
\log (\mathrm{PAs})\end{array}$ & $\begin{array}{c}(4) \\
\log (\mathrm{PAs})\end{array}$ & $\begin{array}{c}(5) \\
\log (\mathrm{PAs})\end{array}$ \\
\hline \multirow[t]{2}{*}{ Remote practice } & 0.154 & & 0.088 & $0.374^{*}$ & 0.301 \\
\hline & (0.194) & & $(0.177)$ & (0.198) & $(0.191)$ \\
\hline \multirow[t]{2}{*}{ Quasi-remote practice } & & & & $0.437^{* *}$ & $0.452^{* *}$ \\
\hline & & & & $(0.175)$ & $(0.179)$ \\
\hline \multirow[t]{2}{*}{ PA cont. subst. } & & 0.196 & 0.125 & & 0.153 \\
\hline & & $(0.198)$ & $(0.195)$ & & $(0.178)$ \\
\hline \multirow[t]{2}{*}{ (Remote Practice) $\times \log ($ MDs office $)$} & -0.039 & & -0.024 & $-0.100 * *$ & $-0.083^{*}$ \\
\hline & $(0.045)$ & & $(0.040)$ & $(0.043)$ & $(0.045)$ \\
\hline \multirow[t]{2}{*}{ (Remote Practice) $\times \log ($ MDs hospital) } & -0.027 & & -0.023 & -0.017 & -0.013 \\
\hline & $(0.025)$ & & $(0.028)$ & $(0.026)$ & $(0.033)$ \\
\hline \multirow[t]{2}{*}{ (Quasi-Remote) $\times \log ($ MDs office $)$} & & & & $-0.121 * * *$ & $-0.125 * * *$ \\
\hline & & & & $(0.044)$ & $(0.044)$ \\
\hline \multirow[t]{2}{*}{ (Quasi-Remote) $\times \log ($ MDs hospital) } & & & & 0.009 & 0.008 \\
\hline & & & & $(0.035)$ & $(0.035)$ \\
\hline \multirow[t]{2}{*}{ (PA Cont. Subst. $) \times \log ($ MDs office $)$} & & -0.039 & -0.026 & & -0.032 \\
\hline & & $(0.050)$ & $(0.050)$ & & $(0.045)$ \\
\hline \multirow[t]{2}{*}{ (PA Cont. Subst.) $\times \log ($ MDs hospital) } & & -0.021 & -0.011 & & -0.011 \\
\hline & & $(0.026)$ & $(0.029)$ & & $(0.029)$ \\
\hline \multirow[t]{2}{*}{$\log$ (MDs office) } & $0.077^{*}$ & 0.076 & $0.082^{*}$ & $0.137^{* * *}$ & $0.146 * * *$ \\
\hline & $(0.041)$ & $(0.046)$ & (0.049) & $(0.035)$ & $(0.041)$ \\
\hline \multirow[t]{2}{*}{$\log ($ MDs hospital) } & $0.099 * * *$ & $0.095^{* * *}$ & $0.103 * * *$ & $0.089 * * *$ & $0.093 * * *$ \\
\hline & (0.018) & $(0.018)$ & (0.019) & $(0.018)$ & $(0.017)$ \\
\hline
\end{tabular}




\begin{tabular}{lcllll} 
Observations & 19,950 & 19,950 & 19,950 & 19,950 & 19,950 \\
R-squared & 0.381 & 0.381 & 0.382 & 0.384 & 0.384 \\
\hline
\end{tabular}

Panel B. Licensing and Liability Laws

\begin{tabular}{|c|c|c|c|c|c|c|}
\hline & $\begin{array}{c}(1) \\
\log (\mathrm{PAs})\end{array}$ & $\begin{array}{c}(2) \\
\log (P A s)\end{array}$ & $\begin{array}{c}(3) \\
\log (\mathrm{PAs})\end{array}$ & $\begin{array}{c}(4) \\
\log (\mathrm{PAs})\end{array}$ & $\begin{array}{c}(5) \\
\log (\mathrm{PAs})\end{array}$ & $\begin{array}{c}(6) \\
\log (\mathrm{PAs})\end{array}$ \\
\hline \multirow[t]{2}{*}{ Remote practice } & & 0.085 & & 0.035 & 0.250 & 0.194 \\
\hline & & $(0.180)$ & & (0.159) & $(0.230)$ & $(0.208)$ \\
\hline \multirow[t]{2}{*}{ Quasi-remote } & & & & & 0.316 & 0.328 \\
\hline & & & & & $(0.212)$ & $(0.212)$ \\
\hline \multirow[t]{2}{*}{ PA cont. subst. } & & & 0.134 & 0.094 & & 0.116 \\
\hline & & & $(0.165)$ & $(0.145)$ & & (0.139) \\
\hline \multirow[t]{2}{*}{ Nonecon. cap } & $0.470 * * *$ & $0.456 * * *$ & $0.457 * * *$ & $0.453 * * *$ & $0.422 * *$ & $0.417^{* *}$ \\
\hline & $(0.147)$ & $(0.149)$ & $(0.142)$ & $(0.146)$ & (0.164) & (0.159) \\
\hline \multirow[t]{2}{*}{$\begin{array}{l}\text { (Remote Practice) } \times \\
\log (\text { MDs office })\end{array}$} & & -0.020 & & -0.009 & -0.067 & -0.054 \\
\hline & & $(0.043)$ & & $(0.038)$ & $(0.053)$ & $(0.050)$ \\
\hline \multirow[t]{2}{*}{$\begin{array}{l}\text { (Remote Practice) } \times \\
\log (\text { MDs hospital) }\end{array}$} & & -0.032 & & -0.029 & -0.022 & -0.019 \\
\hline & & $(0.021)$ & & $(0.024)$ & $(0.022)$ & (0.029) \\
\hline \multirow[t]{2}{*}{$\begin{array}{l}\text { (Quasi-Remote) } \times \\
\log (\text { MDs office })\end{array}$} & & & & & $-0.089 *$ & $-0.092 *$ \\
\hline & & & & & $(0.052)$ & $(0.051)$ \\
\hline \multirow[t]{2}{*}{$\begin{array}{l}\text { (Quasi-Remote) } \times \\
\log (\text { MDs hospital) }\end{array}$} & & & & & 0.010 & 0.009 \\
\hline & & & & & $(0.033)$ & $(0.033)$ \\
\hline \multirow[t]{2}{*}{$\begin{array}{l}\text { (PA Cont. Subst.) } \times \\
\log (\text { MDs office })\end{array}$} & & & -0.025 & -0.020 & & -0.025 \\
\hline & & & $(0.043)$ & $(0.038)$ & & $(0.036)$ \\
\hline \multirow[t]{2}{*}{$\begin{array}{l}\text { (PA Cont. Subst.) } \times \\
\log (\text { MDs hospital) }\end{array}$} & & & -0.022 & -0.008 & & -0.009 \\
\hline & & & $(0.025)$ & $(0.028)$ & & $(0.028)$ \\
\hline \multirow[t]{2}{*}{$\begin{array}{l}\text { (Nonecon. Cap) } \times \\
\log (\text { MDs office })\end{array}$} & $-0.122^{* * *}$ & $-0.119 * * *$ & $-0.119 * * *$ & $-0.118^{* * *}$ & $-0.110 * * *$ & $-0.109 * * *$ \\
\hline & $(0.032)$ & $(0.035)$ & $(0.033)$ & $(0.035)$ & $(0.037)$ & $(0.037)$ \\
\hline \multirow[t]{2}{*}{$\begin{array}{l}\text { (Nonecon. Cap) } \times \\
\log (\text { MDs hospital) }\end{array}$} & $-0.055^{* *}$ & $-0.055^{* *}$ & $-0.055^{* *}$ & $-0.055^{* *}$ & $-0.055^{* *}$ & $-0.055^{* *}$ \\
\hline & $(0.026)$ & $(0.024)$ & $(0.025)$ & $(0.025)$ & $(0.024)$ & $(0.024)$ \\
\hline \multirow[t]{2}{*}{$\log$ (MDs office) } & $0.122 * * *$ & $0.132 * * *$ & $0.134 * * *$ & $0.135 * * *$ & $0.172 * * *$ & $0.178 * * *$ \\
\hline & $(0.027)$ & $(0.035)$ & $(0.038)$ & $(0.040)$ & $(0.041)$ & $(0.045)$ \\
\hline \multirow[t]{2}{*}{$\log ($ MDs hospital) } & $0.101 * * *$ & $0.119 * * *$ & $0.112 * * *$ & $0.121 * * *$ & $0.110 * * *$ & $0.113^{* * *}$ \\
\hline & $(0.013)$ & $(0.019)$ & $(0.020)$ & $(0.021)$ & $(0.020)$ & $(0.021)$ \\
\hline
\end{tabular}




\begin{tabular}{lllllll} 
Observations & 19,950 & 19,950 & 19,950 & 19,950 & 19,950 & 19,950 \\
R-squared & 0.390 & 0.391 & 0.391 & 0.391 & 0.393 & 0.393 \\
\hline
\end{tabular}

Notes: Cont. subst. $=$ controlled substances. The dependent variable in all specifications is the natural logarithm of the number of PAs per 100,000 county residents. Similarly, all physician supply variables are measured in the number of physicians per 100,000 county residents. Counties with no practicing PAs are excluded. All specifications include state and year fixed effects. Additional covariates include population density, the natural logarithm of median household income, the percentage of the population identifying as black or African-American, the percentage of the population identifying as Hispanic, and the percentage of the population eligible for Medicare. Standard errors clustered by state are reported in parentheses. $* * *=$ significant at 1 percent level; $* *=$ significant at 5 percent level; * = significant at 10 percent level.

Next, precisely because the division between the three categories of supervision laws for PAs is more nuanced than for NPs, with a more nebulous division between individual categories (particularly between remote supervision and quasi-remote supervision), I reestimate the models reported in table 3 but combine the remote and quasi-remote categories into a single category of "general remote supervision." These reestimated models ensure that my coding of PA supervision laws is not masking their effect on PA supply. The results are reported in table A5 of the online appendix. States adopting general remote supervision see a 48 percent increase in the supply of PAs at low levels of physician supply, and, as before, the size of this increase decreases as physician supply grows. However, while the effect of general remote supervision is statistically significant in a wider array of specifications than the effects of remote and quasiremote supervision, it is not statistically significant once the noneconomic damages cap variables are included as covariates.

While I find only weak evidence of an effect of licensing laws on PA supply, the effect of noneconomic damages caps on the supply of PAs is both stable across a range of specifications and consistently statistically significant. Focusing on column 1 of panel B, noneconomic damages caps increase the supply of PAs by 60 percent at the lowest levels of physician supply, 
and the size of this increase decreases as physician supply grows. Thus, noneconomic damages caps have a similar effect on PA supply as they do on NP supply.

\section{Extension: The Effect of Licensing and Liability Laws on Health Professional Shortages}

Under federal law, an HPSA exists in an area when (1) it is rational to provide healthcare in that area, (2) the area has more than 3,500 people for every one primary care physician, or more than 3,000 people for every one primary care physician combined with an insufficient capacity of primary care services, and (3) primary care services in nearby areas are not easily accessible (42 C.F.R. § Pt. 5, App. A). Appendix B in the online appendix provides the full text of the criteria used by the federal government to designate an area as an HPSA. ${ }^{23}$ In making this determination, only the number of physicians is considered. However, an increase in the supply of NPs and PAs will still have an indirect effect on whether an area is designated as an HPSA. In particular, an increase in the number of NPs and PAs can impact whether an area has an insufficient capacity of primary care services, which is germane to the second criterion above.

For example, an increase in the number of NPs or PAs could directly affect the following four factors used to determine whether an area has an insufficient capacity of primary care services: "[u]nusually long waits for appointments for routine medical services. . . Excessive average waiting time at primary care providers.... Evidence of excessive use of emergency room facilities for routine primary care... [And a] substantial proportion $(2 / 3$ or more $)$ of the area's physicians do not accept new patients” (42 C.F.R. § Pt. 5, App. A). Traczynski and Udalova (2014) find that relaxing NP licensing laws can reduce wait times and decrease patients' reliance on emergency rooms for primary care services. Additionally, if NPs and PAs are treating

\footnotetext{
${ }^{23}$ HHS - through the Health Resources Services Administration - determines whether an area qualifies as an HPSA and publishes a list of HPSAs in the Federal Register each year.
} 
a greater number of patients, then more physicians will be able to accept new patients. Thus, an increase in the NP or PA supply can indirectly impact whether an area qualifies as an HPSA.

To test whether NP and PA occupational licensing laws increase access to healthcare, I use the regulatory definition of an HPSA as a measure of access. Because the purpose of this analysis is to determine whether the effects of licensing laws on the supply of NPs and PAs described above translate into increases in access to healthcare, the analysis here tracks the above analysis to the greatest extent possible. Data on HPSAs come from the AHRF. HHS began designating HPSAs in 2007, and the AHRF include data on whether any part of each county was designated as an HPSA from 2007 through 2015, except 2014, which is excluded from the analysis. Further, 2007 and 2008 are excluded because not all of the control variables used above are available for these years. ${ }^{24}$ Approximately 83 percent of all counties contained at least one HPSA during the study period. While the analysis of NP and PA supply excluded counties with no practicing NPs or PAs, the analysis here includes all counties regardless of the supply of NPs, PAs, or physicians.

I estimate a series of two-way fixed effects models using the following general specification:

(2) $\mathrm{I}(H P S A)_{\mathrm{cst}}=$ licensing laws ${ }_{\text {st }}^{\prime} \beta_{1}+$ physician supply ${ }_{\text {cst }}^{\prime} \beta_{2}+$

$$
\begin{aligned}
& \text { (licensing laws }) \times(\text { physician supply })_{c s t}^{\prime} \beta_{3}+ \\
& X_{c s t}^{\prime}+\delta_{s}+\tau_{t}+\varepsilon_{c s t}
\end{aligned}
$$

\footnotetext{
${ }^{24}$ Dropping the control variables and including all years for which HPSA designations are available does not change any of the following results in any meaningful way.
} 
This is the same general specification used above, and all of the independent variables in this specification are as defined above. ${ }^{25}$ However, for the dependent variable, I replace the natural logarithm of provider supply with an indicator for whether any part of a given county was designated as an HPSA. And the noneconomic damages cap indicator variable and interactions with this indicator are omitted because the time period over which HHS has designated HPSAs post-dates the time period during which there was state variation - the source of identification for two-way fixed effects models - in the enactment of noneconomic damages caps (Hyman et al. 2015; Avraham 2014). However, results with the noneconomic damages cap indicator included are reported in tables A6 and A7 in the online appendix.

In general, it should be trivially true that an increase in the supply of office-based physicians at the county level decreases the probability that any part of a county is designated as an HPSA (hospital-based physicians are excluded from the counts of physicians used to designate HPSAs). If the NP and PA supply results discussed above translate into changes in access to healthcare, then the licensing and liability law indicators and interactions should have opposite signs in the HPSA regressions relative to the supply regressions.

Table 4 reports regression results for the effect of NP licensing laws on healthcare access. Overall, the results are largely consistent with the NP supply results. In column 1, an increase in the supply of office-based physicians has the anticipated effect, and an increase in hospital-based physicians has the anticipated non-effect. Allowing NPs to practice independently results in a decrease of approximately 12 percentage points in the probability that a county contains an

\footnotetext{
${ }^{25}$ I do not include the supply of NPs or PAs as independent variables. As discussed above, NPs and PAs are more likely than physicians to provide care in underserved areas and do not count towards the number of primary care providers used in determining HPSA status. Therefore, NP and PA supply variables would simply pick up an increased probability of an area being an HPSA in general, especially to the extent that NPs and PAs are the primary or only providers of primary care in underserved areas (Auerbach 2012). Additionally, excluding NP and PA supply variables allows the HPSA analysis to more closely track the supply analysis by maintaining consistency across specifications.
} 
HPSA - a 14 percent decrease in the probability of having an HPSA relative to the national average. In states that allow NP independence, an increase in the supply of physicians has a smaller marginal effect on the probability of a county having an HPSA. This result, combined with the general negative effect of allowing NPs to practice independently, is entirely consistent with the NP supply results. Allowing NPs to practice independently has a large negative effect on counties with relatively fewer practicing physicians, but the magnitude of this effect decreases as the supply of physicians increases. This suggests that, at low levels of physician supply, an increase in NP supply has a larger marginal (positive) effect on primary care capacity than at high levels of physician supply.

Table 4. Regression Results for the Effect of Nurse Practitioner Laws on Provider Shortages

\begin{tabular}{|c|c|c|c|c|c|}
\hline & $\begin{array}{c}(1) \\
\text { I(HPSA) }\end{array}$ & $\begin{array}{c}(2) \\
\text { I(HPSA) }\end{array}$ & $\begin{array}{c}\text { (3) } \\
\text { I(HPSA) }\end{array}$ & $\begin{array}{c}(4) \\
\text { I(HPSA) }\end{array}$ & $\begin{array}{c}(5) \\
\text { I(HPSA) }\end{array}$ \\
\hline \multirow[t]{2}{*}{ NP independence } & $-0.124 * * *$ & & $-0.097 * *$ & $-0.106 * * *$ & $-0.083 * *$ \\
\hline & $(0.033)$ & & $(0.038)$ & $(0.031)$ & $(0.040)$ \\
\hline \multirow[t]{2}{*}{ RX supervision } & & & & 0.075 & 0.071 \\
\hline & & & & $(0.105)$ & $(0.100)$ \\
\hline \multirow[t]{2}{*}{ NP cont. subst. } & & $-0.095 * *$ & -0.066 & & -0.060 \\
\hline & & (0.039) & $(0.043)$ & & $(0.041)$ \\
\hline \multirow[t]{2}{*}{ (Independence) $\times \log ($ MDs office $)$} & $0.026 * * *$ & & $0.019 * *$ & $0.024 * * *$ & $0.018 * *$ \\
\hline & $(0.007)$ & & $(0.007)$ & $(0.007)$ & $(0.008)$ \\
\hline \multirow[t]{2}{*}{ (Independence) $\times \log ($ MDs hospital) } & 0.004 & & 0.004 & 0.000 & 0.001 \\
\hline & $(0.010)$ & & $(0.014)$ & $(0.011)$ & $(0.014)$ \\
\hline \multirow[t]{2}{*}{ (RX Supervision) $\times \log ($ MDs office $)$} & & & & -0.013 & -0.011 \\
\hline & & & & $(0.022)$ & $(0.021)$ \\
\hline \multirow[t]{2}{*}{ (RX Supervision) $\times \log ($ MDs hospital) } & & & & $-0.017^{*}$ & $-0.018^{*}$ \\
\hline & & & & $(0.009)$ & $(0.009)$ \\
\hline \multirow[t]{2}{*}{ (NP Cont. Subst.) $\times \log ($ MDs office $)$} & & $0.020 * *$ & 0.013 & & 0.013 \\
\hline & & $(0.010)$ & $(0.011)$ & & $(0.011)$ \\
\hline \multirow[t]{2}{*}{ (NP Cont. Subst.) $\times$ log(MDs hospital) } & & 0.002 & 0.001 & & -0.003 \\
\hline & & $(0.011)$ & $(0.013)$ & & $(0.013)$ \\
\hline
\end{tabular}




\begin{tabular}{lllllc}
$\log ($ MDs office $)$ & $-0.034^{* * *}$ & $-0.040^{* * *}$ & $-0.040^{* * *}$ & $-0.032^{* * *}$ & $-0.039^{* * *}$ \\
& $(0.006)$ & $(0.009)$ & $(0.009)$ & $(0.006)$ & $(0.008)$ \\
$\log ($ MDs hospital) & -0.002 & -0.002 & -0.002 & 0.002 & 0.004 \\
& $(0.006)$ & $(0.007)$ & $(0.007)$ & $(0.007)$ & $(0.008)$ \\
& & & & & \\
Observations & 18,819 & 18,819 & 18,819 & 18,819 & 18,819 \\
R-squared & 0.187 & 0.186 & 0.187 & 0.188 & 0.188 \\
\hline
\end{tabular}

Notes: Cont. subst. $=$ controlled substances. $\mathrm{RX}=$ prescription. The dependent variable in all specifications is an indicator for whether any part of a county was designated as a primary care HPSA. All physician supply variables are measured in the number of physicians per 100,000 county residents. All specifications include state and year fixed effects. Additional covariates include population density, the natural logarithm of median household income, the percentage of the population identifying as black or African-American, the percentage of the population identifying as Hispanic, and the percentage of the population eligible for Medicare. Standard errors clustered by state are reported in parentheses. $* * *=$ significant at 1 percent level; $* *=$ significant at 5 percent level; $*=$ significant at 10 percent level.

Prescription supervision laws (the intermediate level of supervision for NPs) do not have a statistically significant effect on the probability of a county containing an HPSA. However, laws granting NPs full authority to prescribe controlled substances result in a statistically significant decrease of approximately 9 percentage points - in column 2 - in the probability of having an HPSA. As with NP independence, this effect is largest in counties with the fewest physicians, and the size of the effect decreases as physician supply increases. While these laws had a similar effect on NP supply, that effect was never statistically significant. These laws may have a stronger impact on healthcare access than on NP supply because, while they may not attract a substantial number of NPs, they allow currently practicing NPs to provide a wider range of services, thus increasing the capacity of the primary care workforce and decreasing the probability that an area is designated as an HPSA. In other words, the evidence suggests that these laws do not have a statistically significant effect on the extensive margin because they do not increase the supply of NPs; but they do have a statistically significant effect on the intensive margin because they increase the capacity of existing NPs. 
Table 5 reports regression results for the effect of PA licensing laws on access to healthcare.

There is no statistically significant evidence that PA licensing laws decrease the probability of a county having an HPSA. Estimating specifications that replace the remote and quasi-remote categories with a single general remote category does not meaningfully change the results.

\section{Table 5. Regression Results for the Effect of Physician Assistant Laws on Provider Shortages}

\begin{tabular}{|c|c|c|c|c|c|}
\hline & $\begin{array}{c}(1) \\
\text { I(HPSA) }\end{array}$ & $\begin{array}{c}(2) \\
\text { I(HPSA) }\end{array}$ & $\begin{array}{c}(3) \\
\text { I(HPSA) }\end{array}$ & $\begin{array}{c}(4) \\
\text { I(HPSA) }\end{array}$ & $\begin{array}{c}(5) \\
\text { I(HPSA) }\end{array}$ \\
\hline \multirow[t]{2}{*}{ Remote practice } & -0.027 & & 0.022 & -0.045 & -0.000 \\
\hline & $(0.034)$ & & $(0.055)$ & $(0.047)$ & $(0.061)$ \\
\hline \multirow[t]{2}{*}{ Quasi-remote practice } & & & & -0.033 & -0.047 \\
\hline & & & & $(0.048)$ & $(0.048)$ \\
\hline \multirow[t]{2}{*}{ PA cont. subst. } & & -0.058 & -0.073 & & -0.079 \\
\hline & & $(0.044)$ & $(0.067)$ & & $(0.064)$ \\
\hline \multirow[t]{2}{*}{ (Remote Practice) $\times \log ($ MDs office $)$} & -0.000 & & -0.014 & -0.001 & -0.014 \\
\hline & $(0.010)$ & & $(0.014)$ & $(0.012)$ & $(0.015)$ \\
\hline \multirow[t]{2}{*}{ (Remote Practice) $\times \log ($ MDs hospital) } & $0.020 * *$ & & $0.023^{*}$ & $0.029 * * *$ & $0.031 * *$ \\
\hline & $(0.010)$ & & $(0.012)$ & $(0.010)$ & $(0.012)$ \\
\hline \multirow[t]{2}{*}{ (Quasi-Remote) $\times \log ($ MDs office) } & & & & -0.001 & 0.003 \\
\hline & & & & $(0.015)$ & $(0.014)$ \\
\hline \multirow[t]{2}{*}{ (Quasi-Remote) $\times \log ($ MDs hospital) } & & & & $0.020^{*}$ & $0.020^{*}$ \\
\hline & & & & $(0.011)$ & $(0.011)$ \\
\hline \multirow[t]{2}{*}{ (PA Cont. Subst.) $\times \log ($ MDs office $)$} & & 0.014 & 0.023 & & $0.024 *$ \\
\hline & & $(0.010)$ & $(0.014)$ & & $(0.014)$ \\
\hline \multirow[t]{2}{*}{ (PA Cont. Subst.) $\times \log ($ MDs hospital) } & & 0.011 & -0.001 & & -0.001 \\
\hline & & $(0.010)$ & $(0.011)$ & & $(0.011)$ \\
\hline \multirow[t]{2}{*}{$\log (\mathrm{MDs}$ office) } & $-0.028 * * *$ & $-0.036 * * *$ & $-0.033^{* * *}$ & $-0.027 * * *$ & $-0.035 * * *$ \\
\hline & $(0.008)$ & (0.009) & $(0.008)$ & $(0.010)$ & $(0.012)$ \\
\hline \multirow[t]{2}{*}{$\log (\mathrm{MDs}$ hospital) } & $-0.013^{*}$ & -0.008 & $-0.013 * *$ & $-0.021 * * *$ & $-0.022 * * *$ \\
\hline & $(0.007)$ & $(0.005)$ & $(0.006)$ & $(0.007)$ & $(0.006)$ \\
\hline Observations & 18,819 & 18,819 & 18,819 & 18,819 & 18,819 \\
\hline R-squared & 0.186 & 0.186 & 0.187 & 0.187 & 0.188 \\
\hline
\end{tabular}

Notes: Cont. subst. $=$ controlled substances. The dependent variable in all specifications is an indicator for whether any part of a county was designated as a primary care HPSA. All physician supply variables are measured in the number of physicians per 100,000 county residents. All specifications include state and year fixed effects. Additional covariates include population density, the natural logarithm of median household income, the percentage of the population identifying as black or African-American, the percentage of the population identifying as Hispanic, and 
the percentage of the population eligible for Medicare. Standard errors clustered by state are reported in parentheses. $* * *=$ significant at 1 percent level; $* *=$ significant at 5 percent level; $*=$ significant at 10 percent level.

Overall, the results reported here demonstrate that the supply results reported above translate into meaningful changes in access to healthcare. The effects of NP and PA licensing laws on healthcare access as measured by the presence of federally designated HPSAs are generally consistent with the effects of NP and PA licensing laws on provider supply. This is not to suggest that this is the only possible measure of healthcare access; rather, the analysis here is designed as a general test (using externally defined measures of access) of whether the effects of laws on NP and PA supply translate into changes in access to care. Future work should continue to investigate whether granting NPs and PAs more autonomy and authority increases access to healthcare using different measures of access.

\section{Discussion}

In general, the results demonstrate that relaxing the licensing laws governing NPs and PAs and enacting noneconomic damages caps can increase the supply of NPs and PAs and increase access to healthcare. However, the increase in the supply of NPs and PAs attributable to changes in licensing and liability laws is not simply a "bump" in the number of NPs and PAs in general. Rather, the increase in supply is more of a "backfill," with NPs and PAs locating in areas with relatively low levels of physician supply when licensing and liability laws are amended. Viewed another way, restrictive licensing laws limit the growth in the supply of healthcare providers who could deliver care in communities with relatively few practicing physicians.

The HPSA results demonstrate that the NP and PA supply results translate directly into changes in access to healthcare (with PA licensing laws having a strong effect neither on PA 
supply nor on the probability of having an HPSA). When a state allows NPs to practice independently or prescribe a full range of medications, counties that have few physicians are less likely to contain an HPSA. The HPSA results are particularly instructive because the definition of an HPSA is based on the number of physicians in an area-with NPs excluded from consideration. This means that the changes in the probability of HPSAs must stem from the effect of NP licensing laws on the capacity of the primary care workforce. With more NPs (who can provide more services), the capacity of the primary care workforce can expand without the need for more physicians, thus making an area less likely to qualify for HPSA status. In other words, the results are consistent with NP licensing laws acting as a relief valve to decrease the pressure on the existing physician supply.

Overall, the results are generally consistent with prior research on licensing and liability laws. However, the results here extend the existing literature by specifically demonstrating that, consistent with the hypothesis of the FTC (Gilman and Koslov 2014, 30), restrictive licensing laws limit access to healthcare professionals in areas that already lack access. Moreover, while no prior research has empirically investigated the effect of tort reform on NPs and PAs, the results here suggest that noneconomic damages caps can increase the supply of NPs and PAs but that this increase in supply is concentrated in areas with few practicing physicians.

While the results here support the conclusion that relaxing NP and PA licensing laws and enacting noneconomic damages caps increases the supply of these providers and access to care more generally, these results do not prove that relaxed licensing laws or tort reforms are unequivocally welfare-enhancing. Healthcare policy typically revolves around three axes: access, cost, and quality. The results here provide evidence that access is improved, but they do not speak directly to cost or quality. In general, most prior work has found that relaxing licensing 
laws reduces costs (e.g., Kleiner et al. 2016; Timmons et al. 2016), but some research suggests NPs and PAs have limited impacts on cost (e.g., Stange 2014). Similarly, while previous work has demonstrated that NPs and PAs generally provide care of similar quality as physicians (e.g., Newhouse et al. 2011), other work has found that they order more tests than their physician colleagues (Hughes et al. 2015). For tort reforms, the evidence here and prior work (e.g., Avraham and Schanzenbach 2010; Matsa 2007; Helland and Seabury 2015) suggest that noneconomic damages caps can increase access to care, but these reforms may impose costs on plaintiffs by reducing plaintiffs' ability to obtain compensation for injuries (see, e.g., Friedson and Kniesner 2012). Additionally, to the extent that tort reforms reduce malpractice risk, they may undermine deterrence, and prior work has found that malpractice liability can encourage the provision of safe care (see, e.g., Black et al. 2016). Overall, the debate over licensing laws and tort reforms is likely to continue, and the results presented here can inform policymakers of the effect of these laws on a critical part of that debate - access - as they continue to evaluate the best ways to regulate the healthcare workforce.

\section{Sensitivity and Robustness Analysis}

\section{Alternative Specifications}

In the interest of succinctness, results from the primary robustness checks are reported in the online appendix. Throughout the analysis, the standard errors in each specification are clustered at the state level. However, standard errors may be correlated at the year level in addition to the state level. To account for arbitrary autocorrelation within states and years, I cluster standard errors by both state and year using the multiway clustering procedure described in Cameron et al. (2011). Tables A8 and A9 report results for the same specifications that were reported in tables 2 
and 3 but with two-way clustered standard errors at both the state and year levels. Allowing for multiway clustering does not meaningfully change the previously reported results.

Beyond changing how the standard errors are calculated, I test whether the results are sensitive to the underlying specifications. I first drop all control variables and then systematically drop individual controls and groups of control variables. Doing so results in only small movements in the estimated coefficients with no meaningful changes in statistical significance. I next add additional controls for other tort reforms — collateral source rule reform, joint and several liability rule reform, and punitive damages caps. Adding indicator variables for these reforms does not substantially change the coefficient estimates or the statistical significance of the above results. Next, along the lines of Li et al. (2017) and Avraham et al. (2012), I include a simple count variable for the following tort reforms: noneconomic damages cap, punitive damages cap, collateral source rule reform, periodic payment reform, and joint and several liability reform. Including this variable does not meaningfully affect the results. Finally, I include controls for the passage of the ACA and for whether a state had a certificate of need law in place. ${ }^{26}$ Neither of these variables substantially impacts the results.

While all specifications include state and year fixed effects, it is possible that the licensing and liability law variables are simply picking up temporal trends in the increase of providers. To address this concern, I include a series of state-specific linear time trends in the empirical models. Including time trends also addresses some concerns that the temporal gap in the data is biasing the results. Specifications that are identical to those reported in tables 2 and 3 but include state-specific linear time trends are reported in tables A10 and A11. Though the point estimates change somewhat, the pattern of results described above remains unchanged. To

\footnotetext{
${ }^{26}$ These laws essentially require state approval for the expansion of the number of hospital beds, certain types of medical equipment, and so on. (see Mitchell and Koopman 2016).
} 
further address the concern that the temporal gap is driving the results, tables A12 and A13 report results using data from 2010 forward. These years exclude state variation in noneconomic damages caps, but the licensing law results are consistent with earlier reported results.

\section{Randomization Inference}

As noted by Frakes (2013), when there are a limited number of treatment or analytical groups, standard errors may not be accurately estimated in two-way fixed effects specifications (see also Bertrand et al. 2004; Conley and Taber 2005). To address this concern, I employ a similar approach as Frakes (2013) and Werner and Coleman (2015) by randomly assigning licensing and liability law "treatment" to different states in my sample to generate 5,000 sets of placebo laws. I then reestimate all of the above specifications on each of these simulated sets. More specifically, I maintain the year of enactment for all of the licensing and liability law indicator variables described in the main analysis and randomly assign different states to those years of enactment. Beyond addressing issues related to the number of overall analytical and treated units, randomization methods can also address concerns regarding selection on observables (Sekhon 2009) and can produce better inferences than those based on clustered standard errors and standard asymptotic assumptions (Barrios et al. 2012; see also Werner and Coleman 2015).

I find that the actual estimated coefficients that are statistically significant in the main specifications fall in the tails of the distributions of coefficients derived from the simulations based on the placebo laws. Similarly, the coefficients for the interaction between the actual laws and the supply of physicians (which are never randomly assigned) fall in the tails of the 
distributions of coefficients for the interaction terms based on the placebo laws. ${ }^{27}$ In general, no actual estimated coefficient for any licensing or liability law (or coefficients for interactions with these variables) that is statistically significant in the main specifications falls above the 2nd percentile (and they often fall below the 0.5 th percentile) of the distribution of the 5,000 estimated coefficients from the placebo law simulations. Falling in the 2 nd percentile is consistent with a p-value of less than 0.05 , and the estimated p-values are often below 0.01 based on the placebo law distributions. This suggests that the effects estimated above are robust and represent causal relationships.

\section{Event Study Models}

As with all empirical approaches that involve estimating two-way fixed effects models, a potential concern is that indicator variables for legal changes are simply picking up pre-existing trends in the dependent variable. To address this concern, I estimate a series of event study models that include the following variables for each licensing law: an indicator that equals one in the year a law is coded as taking effect; one-, two-, and three-year leads; one-, two-, and threeyear lags; and an indicator for being four or more years beyond the year a law took effect. Results from these models are reported in tables A14 and A15 in the online appendix. ${ }^{28}$ For NPs, there is no evidence that states were responding to increases in NP supply when passing laws granting NPs more autonomy. In fact, the coefficients on the three- and two-year lead terms for NP independence are negative and statistically significant. The one-year lead terms for NP

\footnotetext{
${ }^{27}$ Figure A1 in the appendix is an example of where the actual estimated coefficient of a licensing law (NP independence) and coefficients for the interaction between this law and physician supply fall relative to the placebo distributions.

${ }^{28}$ In the interests of succinctness and readability, tables A14 and A15 report only the event study models that correspond to the models reported in first columns of tables 2 and 3, respectively.
} 
independence generally have positive coefficients, but they are not statistically significant. And these positive coefficients may stem from the coding of the licensing law variables-when a law takes effect in the second half of the year, it is coded as first taking effect in the following calendar year. For PAs, the estimated coefficients on the lead and lag terms are generally statistically insignificant and do not clearly support either the conclusion that there was no increase in PA supply prior to the passage of the law or the conclusion that the passage of a broader PA licensing law clearly increased PA supply.

While I find no consistent, statistically significant evidence that the licensing laws considered in the primary analysis are simply picking up pre-existing increases in provider supply, a salient limitation of my data is the temporal gap between 2001 and 2010. This temporal gap also prevents me from examining potential pre-trends in NP or PA supply that may be picked up by the noneconomic damages cap variable because the state variation in noneconomic damages caps occurred prior to 2010. However, examining noneconomic damages caps in this context may not be informative of the existence of a pre-trend in any event, as healthcare providers may anticipate forthcoming tort reforms and change their behavior before the reform is enacted (see Malani and Reif 2015).

\section{Endogeneity: Licensing and Liability Laws}

While I find no evidence that states respond to increasing supplies of providers by passing new licensing laws, if states respond to other factors not considered here, the results may be biased. One particular point of concern is the possibility that states respond to the political strength of interest groups associated with different professions. As noted by Stange (2014), if states respond to increased political power of NP, PA, or physician groups, the models reported above 
may be picking up this increase in strength rather than the effect of the laws themselves. And McMichael (2017) finds that political spending does, in fact, motivate states to change their licensing laws. However, McMichael (2017) finds no evidence (1) that increased political spending is associated with increases in the supply of different professionals in the future or (2) that the size of the supply of different professionals has a statistically significant effect on per capita political spending or the probability that states enact different laws. These latter results suggest that while political spending may play a role in encouraging states to enact different licensing laws, the estimated effects above are not simply picking up political factors such as changes in spending.

With respect to the potential endogeneity of noneconomic damages caps, almost all prior work on the effect of tort reforms on physician supply has treated those reforms as exogenous. Danzon (1984) and Campbell et al. (1995) show that tort reforms, especially damages caps, generally do not respond to physician political power. In general, political groups associated with NPs and PAs do not prioritize medical malpractice reform as highly as physician groups, so if the latter do not affect the passage of tort reforms, the former are even less likely to do so. Klick and Stratmann (2007) and Matsa (2007) treat tort reforms as exogenous. However, more recently, Lieber (2014) employs an empirical strategy that addresses the potential endogeneity of tort reforms with physician supply — though he explains that addressing this potential endogeneity was not the primary motivating factor in employing this empirical strategy.

Although the available evidence suggests that neither licensing laws nor tort reforms are endogenously determined with NP or PA supply, I nevertheless perform two separate robustness checks to confirm that the estimated results do not suffer from endogeneity bias. First, to address the concern that, beyond political influence, other omitted variables may be influencing the 
results, I test for omitted variable bias generally, employing the approach developed by Oster (2017). This method is based on prior work by Altonji et al. (2008), Tamer (2010), and Manski (2003), and it involves a proportional selection assumption. Specifically, I assume that the amount of selection of the potentially endogenous variable on the other control variables is proportional to the amount of selection on unobserved variables, with this latter selection representing the extent of any endogeneity bias. Based on Oster (2017) and Altjoni et al. (2008), I assume equal selection-i.e., I assume that the amount of selection on the observed and unobserved variables is the same - and a conservative estimate for the maximum R-squared in my models. Based on these assumptions, and following Tamer (2010) and Manksi (2003), I then construct an identified set for every licensing and liability law variable as well as for the interaction between these variables and the physician supply variables. Oster (2017) explains that the exclusion of zero from the identified set provides evidence of a causal effect. The identified sets for the coefficients reported in tables 2 and 3 are reported in tables A16 and A17, respectively. Every identified set associated with a statistically significant variable in tables 2 and 3 excludes zero.

Second, although the test for omitted variable bias developed by Oster (2017) provides evidence of causality, it cannot rule out all forms of endogeneity bias (e.g., reverse causality). To address other potential sources of bias, I follow Lieber's (2014) approach. Specifically, I examine changes in the supply of NPs and PAs in counties neighboring other states in response to changes in licensing and liability laws in those border states. By focusing on changes in the laws of neighboring states, this strategy addresses the concern that changes in provider supply cause changes in licensing and liability laws instead of vice versa. This empirical strategy relies 
on the ability of providers in counties bordering other states to relatively easily relocate their practices to neighboring states in response to legal changes in those states.

I use the same general specification described above, but I drop all counties that do not border another state - this necessarily excludes all of Alaska and Hawaii. Consistent with Lieber (2014), each licensing law indicator and the noneconomic damages cap indicator is constructed as a population weighted average of the relevant laws in all counties that both border a given county and are located within a different state. These variables take values between 0 and 1 when a given county borders counties in multiple neighboring states. I also replace the physician supply variables used above with population-weighted averages of the supply of office- and hospital-based physicians in border counties located in different states. To demonstrate that the above results do not suffer from endogeneity bias, the estimates from this empirical approach should have the opposite sign from the estimates reported in tables 2 and $3 .{ }^{29}$

Results from this border county analysis are reported in tables A18 and A19, and I find that, generally, the licensing and liability law variables have the opposite signs from the coefficients estimated above, are generally smaller in magnitude, and are not consistently statistically significant. Although the estimated coefficients are not universally statistically significant, the fact that they have the opposite signs from the results above suggests that the main results do not suffer from endogeneity bias. The lack of statistical significance could stem from the nature of the empirical strategy, which relies on counties that share a border with a

\footnotetext{
${ }^{29}$ They should have the opposite sign because in these border county specifications, I am essentially estimating whether a neighboring state's legal change "drains" NPs or PAs from a county bordering that state. For example, consider county A in state AA, which borders county B in state BB. State AA changes its physician supervision requirements for NPs from complete supervision to independence. The main empirical strategy involves estimating the increase in NP supply in county A (and other counties in state AA) directly. Based on Lieber's (2014) approach, I estimate the effect of the change in state AA's law on the NP supply in county B. County B is not directly affected - it is governed by state BB's law - but if granting NPs greater autonomy actually increases NP supply, then the NP supply in county B, which borders county A, should decrease as NPs migrate to county A because they prefer working in a state that grants them independence.
} 
neighboring state being treated by that state's legal changes to a greater extent than counties that are close to, but do not border, the neighboring state (Lieber 2014).

\section{Endogeneity: Physician Supply and Legal Changes}

If licensing and liability laws affect physician supply directly, the results above may be biased. In particular, if physician supply is directly affected by legal changes, the change in the elasticity between physicians and NPs and PAs, which is estimated by the interaction between legal indicator variables and physician supply variables, may be over- or under-stated. To test the effect of licensing and liability laws on the supply of physicians, I estimate a series of two-way fixed effects specifications with the supply of office- and hospital-based physicians as the dependent variables. These results are reported in tables A20-A23 in the online appendix, and in general, I find no consistent, statistically significant effect of any licensing or liability law on either measure of physician supply. Because the effect of licensing and liability laws on NP and PA supply vary across different levels of physician supply, I further test whether these laws affect physician supply differently across the distribution of physician supply. I estimate a series of quantile regressions at the 10th, 25th, 50th, 75th, and 90th percentiles of the distribution of physician supply and find no evidence that licensing or liability laws affect physician supply at any point in the distribution.

These results are not surprising based on the existing literature. The effect of noneconomic damages caps on physician supply has been well studied (Helland and Seabury 2015). Some studies find that noneconomic damages caps increase physician supply by around 2 percent, but many of the studies that find an effect of caps find this effect only for physicians in high-risk specialties (Helland and Seabury 2015). Helland and Seabury (2015), studying a later 
wave of tort reforms, find some evidence that damages caps are associated with a smaller physician supply. My study is not restricted to the subsets of physicians that prior work has found are affected by tort reforms. To the extent that noneconomic damages caps affect the mix of the physician supply (high-risk specialties versus low-risk specialties), there is no reason to expect that physicians in specialties that involve different levels of risk supervise or work with NPs and PAs at different rates.

The lack of an effect of licensing laws on physician supply raises interesting questions about the nature of competition in healthcare services markets between NPs, PAs, and physicians. One potential explanation is that NPs and PAs simply take the care provided by physicians as a given and "backfill" in areas lacking care provided by physicians-i.e., physicians get "first choice" of patients as mentioned above. Another explanation is that physicians respond to increased competition by NPs and PAs by simply shifting the care they provide to services outside the training and education of NPs and PAs. Future work may further explore the nature of competition between NPs, PAs, and physicians, and the results here can provide insight into which types of competition should be explored first.

\section{Conclusion}

This paper is the first to assess the effects of both licensing and liability laws on the supply of NPs and PAs across all 50 states over time. My findings demonstrate that relaxing the licensing laws governing NPs and (to a lesser extent) PAs and enacting noneconomic damages caps can increase the supply of these providers in areas with relatively few physicians. These results are consistent with prior work finding that NPs and PAs are more likely to provide care in underserved areas. These findings suggest that relaxing licensing laws or enacting tort reforms 
better enables NPs and PAs to provide care in these underserved areas. I also confirm that the increases in NP and PA supply translate into increases in access to healthcare using the federal government's definition of an HPSA. These results can inform policymakers as they continue to evaluate the best ways to regulate the healthcare workforce. 


\section{References}

Allensworth, Rebecca Haw. Forthcoming. "Foxes at the Henhouse: Occupational Licensing Boards Up Close." California Law Review 105.

Altonji, Joseph G., Todd Elder, and Christopher R. Taber. 2008. "Using Selection on Observed Variables to Assess Bias from Unobservables When Evaluating Swan-Ganz Catheterization." American Economic Review 98: 345-50.

American Medical Association. 2017. Medical Liability Reform-Now! https://www.amaassn.org/sites/default/files/media-browser/premium/arc/mlr-now.pdf.

Avraham, Ronen. 2007. "An Empirical Study of the Impact of Tort Reforms on Medical Malpractice Settlement Payments.” Journal of Legal Studies 36: S183-S229.

- 2012. "The Impact of Tort Reform on Employer-Sponsored Health Insurance Premiums." Journal of Law, Economics, and Organization 28: 657-86.

- 2014. "Database of State Tort Law Reforms (DSTLR 5th)." University of Texas Law, law and economics research paper no. e555. Available through SSRN at http://papers.ssrn.com/sol3/papers.cfm?abstract_id=902711.

Avraham, Ronen, and Max Schanzenbach. 2010. "The Impact of Tort Reform on Private Health Insurance Coverage." American Law and Economics Review 10: 319-55.

- 2015. "The Impact of Tort Reform on Intensity of Treatment: Evidence from Heart Patients." Journal of Health Economics 39: 273-88.

Auerbach, David. 2012. "Will the NP Workforce Grow in the Future? New Forecasts and Implications for Healthcare Delivery." Medical Care 50: 606-10.

Barrios, Thomas, Rebecca Diamond, Guido W. Imbens, and Michal Kolesar. 2012. "Clustering, Spatial Correlations, and Randomization Inference." Journal of the American Statistical Association 107: 578-91.

Bertrand, Marianne, Esther Duflo, and Sendhil Mullainathan. 2004. "How Much Should We Trust Differences-in-Differences Estimates?" Quarterly Journal of Economics 119: 24975.

Black, Bernard S., Amy R. Wagner, and Zenon Zabinski. 2016. "The Association between Patient Safety Indicators and Medical Malpractice Risk: Evidence from Florida and Texas." Northwestern University Pritzker School of Law, law and economics research paper no. 11-20. Available through SSRN at http://ssrn.com/abstract=1884630.

Born, Patricia, W. Kip Viscusi, and Tom Baker. 2009. "The Effects of Tort Reform on Medical Malpractice Insurers' Ultimate Losses." Journal of Risk and Insurance 76: 197-219. 
Brock, Douglas M., Jeffrey G. Nicholson, and Roderick S. Hooker. 2017. "Do PAs or NPs Increase the Liability of a Medical Practice?" Medical Care Research and Review, forthcoming.

Cameron, Colin A., Jonah B. Gelbach, and Douglas L. Miller. 2011. "Robust Inference with Multiway Clustering." Journal of Business and Economic Statistics 29: 238-49.

Campbell, Thomas J., Daniel P. Kessler, and George B. Shepherd. 1995. "The Causes and Effects of Liability Reform: Some Empirical Evidence.” NBER Working Paper no. 4989. National Bureau of Economic Research, Cambridge, MA.

Conley, Timothy G., and Christopher R. Taber. 2011. "Inference with 'Difference in Differences' with a Small Number of Policy Changes." Review of Economics and Statistics 93: 113-25.

Danzon, Patricia M. 1984. "The Frequency and Severity of Medical Malpractice Claims." Journal of Law and Economics 27: 115-148.

Declerq, Eugene, Lisa Paine, Diana Simmes, and Jeanne DeJoseph. 1998. "State Regulation, Payment Policies, and Nurse-Midwife Services.” Health Affairs 17: 190-200.

Donohue, John J. III, and Daniel E. Ho. 2007. "The Impact of Damages Caps on Malpractice Claims: Randomization Inference with Difference-in-Difference." Journal of Empirical Legal Studies 4: 69-102.

Dueker, Michael J., Ada K. Jacox, David E. Kalist, and Stephen J. Spurr. 2005. "The Practice Boundaries of Advanced Practice Nurses: An Economic and Legal Analysis." Journal of Regulatory Economics 27: 309-29.

Dunker, Amanda, Esther Krofah, and Frederick Isasi. 2014. The Role of Physician Assistants in Health Care Delivery. Washington, DC: National Governors Association Center for Best Practices.

Encinosa, William E., and Fred J. Hellinger. 2005. "Have State Caps on Malpractice Awards Increased the Supply of Physicians?" Health Affairs 24: supplement web exclusives 25058.

Everett, C., J. Schumacher, A. Wright, M. Smith. 2009. "Physician Assistants and Nurse Practitioners as Usual Source of Care.” Journal of Rural Health 25: 407-14.

Frakes, Michael A., and Tracylain Evans. 2006. "An Overview of Medicare Reimbursement Regulations For Advanced Practice Nurses.” Nursing Economics 24: 59-65.

Frakes, Michael D. 2013. "The Impact of Medical Liability Standards on Regional Variations in Physician Behavior: Evidence from the Adoption of National-Standard Rule." American Economic Review 103: 257-276. 
Friedson, Andrew I., and Thomas J. Kniesner. 2012. "Losers and Losers: Some Demographics of Medical Malpractice Tort Reforms.” Journal of Risk and Uncertainty 45: 115-33.

Halvorsen, Robert, and Raymond Palmquist. 1980. "The Interpretation of Dummy Variables in Semilogarithmic Equations.” American Economic Review 70: 474-75.

Helland, Eric, and Seth A. Seabury. 2015. "Tort Reform and Physician Labor Supply: A review of the Evidence." International Review of Law and Economics 42: 192-202.

Helland, Eric, and Mark H. Showalter. 2009. "The Impact of Liability on the Physician Labor Market.” Journal of Law \& Economics 52: 635-63.

Hooker, Roderick S., Jeffrey G. Nicholson, and Tuan Le. 2009. "Does the Employment of Physician Assistants and Nurse Practitioners Increase Liability?” Journal of Medical Licensure and Discipline 95: 6-16.

Hughes, Danny R., Miao Jiang, and Richard Duszak. 2015. “A Comparison of Diagnostic Imaging Ordering Patterns Between Advanced Practice Clinicians and Primary Care Physicians Following Office-Based Evaluation and Management Visits." JAMA Internal Medicine 175:101-07.

Hyman, David A., Charles Silver, Bernard Black, and Myungho Paik. 2015. "Does Tort Reform Affect Physician Supply? Evidence from Texas." International Review of Law and Economics 42: 203-18.

Institute of Medicine. 2011. The Future of Nursing: Leading Change, Advancing Health. Washington, DC: National Academies Press.

Gilman, Daniel J. and Tara Isa Koslov. 2014. "Policy Perspectives: Competition and the Regulation of Advanced Practice Nurses." Federal Trade Commission policy paper.

Grumbach, Kevin, L. Gary Hart, Elizabeth Mertz, Janet Coffman, and Lorella Palazzo. 2003. "Who Is Caring for the Underserved? A Comparison of Primary Care Physicians and Nonphysician Clinicians in California and Washington." Annals of Family Medicine 1: 97-104.

Kalist, David E., and Stephen J. Spurr. 2004. "The Effect of State Laws on the Supply of Advanced Practice Nurses." International Journal of Health Care Finance and Economics 4: 271-81.

Kessler, Daniel P., William M. Sage, and David J. Becker. 2005. "Impact of Malpractice Reforms on the Supply of Physicians Services." Journal of the American Medical Association 293: 2618-25.

Kleiner, Morris M. 2006. Licensing Occupations: Ensuring Quality or Restricting Competition? Kalamazoo, Michigan: W. E. Upjohn Institute for Employment Research. 
Kleiner, Morris M. and Kyoung Won Park. 2010. "Battles Among Licensed Occupations: Analyzing Government Regulations on Labor Market Outcomes for Dentists and Hygienists.” NBER Working Paper no. 16560. National Bureau of Economic Research, Cambridge, MA.

Kleiner, Morris M., Allison Marier, Kyoung Won Park, and Coady Wing. 2016. "Relaxing Occupational Licensing Requirements: Analyzing Wages and Prices for a Medical Service." Journal of Law and Economics 59: 261-91.

Klick, Jonathan, and Thomas Stratmann. 2007. "Medical Malpractice Reform and Physicians in High Risk Specialties.” Journal of Legal Studies 36: S121-42.

Larson, Eric H., Lorella Palazzo, Bobbi Berkowitz, Michael J. Pirani, and L. Gary Hart. 2003. "The Contribution of Nurse Practitioners and Physician Assistants to Generalist Care in Washington State.” Health Services Research 38: 1033-50.

Li, Suhui, Avi Dor, Darwyyn Deyo, and Danny R. Hughes. 2017. "The Impact of State Tort Reforms on Imaging Utilization." Journal of the American College of Radiology 14: 149-56.

Lieber, Ethan. 2014. "Medical Malpractice Reform, the Supply of Physicians, and Adverse Selection." Journal of Law and Economics 57: 501-27.

Malani, Anup, and Julian Reif. 2015. "Interpreting Pre-Trends as Anticipation: Impact on Estimated Treatment Effects of Tort Reform.” Journal of Public Economics 124: 1-17.

Manski, Charles F. 2003. Partial Identification of Probability Distributions. New York: Springer International Publishing.

Matsa, David A. 2007. "Does Malpractice Liability Keep the Doctor Away? Evidence from Tort Reform Damage Caps.” Journal of Legal Studies 36: S143-S182.

McMichael, Benjamin J. 2017. "The Demand for Healthcare Regulation: The Effect of Political Spending on Occupational Licensing Laws.” Southern Economic Journal 84: 297-316.

Mello, Michelle, Allen Kachalia, and Sarah Goodell. 2006. "Medical Malpractice: Impact of the Crisis and Effect of State Tort Reforms." New Brunswick, NJ: Robert Wood Johnson Foundation, Research Synthesis Report \#10.

Mitchell, Matthew D., and Christopher Koopman. 2016. "40 Years of Certificate-of-Need Laws Across America." Mercatus Center at George Mason University, Arlington, VA. https://www.mercatus.org/publication/40-years-certificate-need-laws-across-america.

Naylor, Mary, and Ellen Kurtzman. 2010. "The Role of Nurse Practitioners in Reinventing Primary Care.” Health Affairs 29: 893-99. 
Newhouse, Robin P., Julie Stanik-Hutt, Kathleen M. White, Meg Johantgen, Eric B. Bass, George Zangaro, Renee F. Wilson, Lily Fountain, Donald M. Steinwachs, Lou Heindel, and Jonathan P. Weiner. 2011. "Advanced Practice Nurse Outcomes, 1990-2008: A Systematic Review.” Nursing Economics 29: 230-50.

Oster, Emily. 2017. "Unobservable Selection and Coefficient Stability: Theory and Evidence." Journal of Business \& Economic Statistics, forthcoming.

Paik, Myungho, Bernard Black, and David A. Hyman. 2016. "Damage Caps and the Labor Supply of Physicians: Evidence from the Third Reform Wave." American Law and Economics Review 18: 463-505.

Perry, John J. 2009. "The Rise and Impact of Nurse Practitioners and Physician Assistants on Their Own and Cross-Occupation Incomes." Contemporary Economic Policy 27: 491511.

Schiff, Maria. 2012. The Role of Nurse Practitioners in Meeting Increasing Demands for Primary Care. Washington, DC: National Governors Association Center for Best Practices.

Sekhon, Jasjeet S. 2009. "Opiates for the Matches: Matching Methods for Causal Inference." Annual Review of Political Science 12: 487-508.

Sekscenski, Edward, Stephanie Sansom, Carol Bazell, Marla Slamon, and Fitzhugh Mullan. 1994. "State Practice Environments and the Supply of Physician Assistants, Nurse Practitioners, and Certified Nurse-Midwives." New England Journal of Medicine 331: $1266-71$.

Stange, Kevin. 2014. "How Does Provider Supply and Regulation Influence Health Care Markets? Evidence from Nurse Practitioners and Physician Assistants." Journal of Health Economics 33: 1-27.

Tamer, Elie. 2010. "Partial Identification in Econometrics." Annual Review of Economics 9: 167-95.

Timmons, Edward Joseph. 2017. "The Effects of Expanded Nurse Practitioner and Physician Assistant Scope of Practice on the Cost of Medicaid Patient Care." Health Policy, forthcoming.

Traczynski, Jeffrey, and Victoria Udalova. 2014. "Nurse Practitioner Independence, Health Care Utilization, and Health Outcomes." Working paper. Available through the University of Hawaii at http://www2.hawaii.edu/ jtraczyn/paperdraft_050414_ASHE.pdf.

Viscusi, W. Kip, and Patricia H. Born. 2005. "Damage Caps, Insurability, and the Performance of Medical Malpractice Insurance.” Journal of Risk and Insurance 72: 23-43. 
Werner, Timothy, and John J. Coleman. 2015. "Citizens United, Independent Expenditures, and Agency Costs: Reexamining the Political Economic of State Antitakeover Statutes." Journal of Law, Economics, \& Organization 31: 127-59.

Wooldridge, Jeffrey M. 2002. Econometric Analysis of Cross Section and Panel Data. Cambridge, Massachusetts: MIT Press.

Yang, Y. Tony, David M. Studdert, S. V. Subramanian, Michelle M. Mello. 2008. “A Longitudinal Analysis of the Impact of Liability Pressure on the Supply of ObstetricianGynecologists." Journal of Empirical Legal Studies 5: 21-53. 